IZA DP No. 10309

Conditional Cash Transfers:

Do They Change Time Preferences and

Educational Aspirations?

Diana Contreras Suarez

Lisa Cameron

October 2016 


\title{
Conditional Cash Transfers: Do They Change Time Preferences and Educational Aspirations?
}

\author{
Diana Contreras Suarez \\ Monash University \\ Lisa Cameron \\ Monash University \\ and IZA
}

Discussion Paper No. 10309

October 2016

\author{
IZA \\ P.O. Box 7240 \\ 53072 Bonn \\ Germany \\ Phone: +49-228-3894-0 \\ Fax: +49-228-3894-180 \\ E-mail: iza@iza.org
}

Any opinions expressed here are those of the author(s) and not those of IZA. Research published in this series may include views on policy, but the institute itself takes no institutional policy positions. The IZA research network is committed to the IZA Guiding Principles of Research Integrity.

The Institute for the Study of Labor (IZA) in Bonn is a local and virtual international research center and a place of communication between science, politics and business. IZA is an independent nonprofit organization supported by Deutsche Post Foundation. The center is associated with the University of Bonn and offers a stimulating research environment through its international network, workshops and conferences, data service, project support, research visits and doctoral program. IZA engages in (i) original and internationally competitive research in all fields of labor economics, (ii) development of policy concepts, and (iii) dissemination of research results and concepts to the interested public.

IZA Discussion Papers often represent preliminary work and are circulated to encourage discussion. Citation of such a paper should account for its provisional character. A revised version may be available directly from the author. 


\title{
ABSTRACT
}

\section{Conditional Cash Transfers: Do They Change Time Preferences and Educational Aspirations?}

\begin{abstract}
Conditional Cash Transfer programs are designed to increase human capital in poorer families. They do this directly through incentives and conditions. A further way these programs may influence household decisions is through impacts on preferences. Preferences may change as a result of new habit formation, information received through the program or by the relaxation of budget constraints which gives households a greater ability to look beyond their daily needs to plan for the future. Using a regression discontinuity design we test whether a large CCT program in Colombia affects the time preferences of participating households and aspirations for their children's education. We find that it does not. Thus, the positive impacts identified in previous studies appear to be driven by the ongoing receipt of the cash transfers and the associated conditions. Hence if the transfers were to stop, program benefits would likely be limited to those obtained during the program.
\end{abstract}

JEL Classification: $\quad$ O15, I25, I38, D91

Keywords: conditional cash transfers, time preferences, educational aspirations, regression discontinuity design, Colombia

Corresponding author:

Diana Contreras Suarez

Department of Econometrics and Business Statistics

Monash University

Wellington Rd

Clayton, 3800, Vic.

Australia

E-mail: Diana.Contreras.Suarez@monash.edu 


\section{Introduction}

Over the past two decades many developing countries have implemented Conditional Cash Transfers (CCTs) in order to increase human capital in poor households and break the intergenerational transmission of poverty. CCT programs consist of regular stipends given to poor households, on the condition that they invest in the human capital of their children, normally through conditions on school attendance and child health visits. The conditions and monetary incentives are often justified on the basis of overcoming distortions in parents' decision-making. The observed low investments in children's human capital formation could, for example, be a result of liquidity or credit constraints (Lawrance, 1991); low expectations of returns to education (Attanasio and Kaufmann (2009), Jensen (2010)); low parental internalization of the positive social externalities of education (De Janvry and Sadoulet, 2005); parental agency problems where parents make decisions over children's education and labour and do not consider children's future wellbeing (Edmonds, 2007); or parental impatience, irrationality and low self-control (Basu (2003); Das et al. (2005); Das (2007)).

There is now extensive evidence showing that CCTs change behaviour - increases in medical visits, improved nutrition and health; higher school enrollment and attendance (see Fiszbein et al. (2009) for a review). The Colombian program studied here - Familias en Acción - has been shown to increase the enrolment rate of children aged 14 to 17 by 5.6 percentage points (O. Attanasio et al., 2010), the probability of finishing high school in rural areas by 6 percentage points (Baez and Camacho, 2011), the number of children who have regular visits to medical check-ups by around $28 \%$ (Attanasio et al., 2005) and total consumption and food consumption by $13.3 \%$ and $15.9 \%$ respectively (Attanasio et al., 2012). Are the health and educational improvements merely a direct result of the monetary incentives or do participants' preferences change as a result of the exposure to the program? Baird et al. (2014), in a systematic review of the effects of cash transfer programs, provide evidence that the conditions, when monitored and enforced, are an important contributor to program success but little is known about the role of preference change.

This paper aims to contribute to our knowledge of the underlying mechanisms via which CCT programs work. Using a Regression Discontinuity (RD) design, we explore whether participation in Familias en Acción has an effect on parents' time preferences and aspirations for their chil- 
dren's education. We are able to examine whether parental preferences change while in receipt of the transfer, and over a period of up to nine years after exiting the program. If CCTs merely operate through the monetary incentives, if the program were to stop parents may no longer choose to send their children to school. However, if CCT programs change underlying parents' preferences, we would expect to see a sustained increase in enrolments and nutrition even if the conditional transfers ceased. Any changes in parents' time preferences could also significantly magnify the benefits of such programs via potential positive impacts on other outcomes, such as household savings, incomes and health decisions. Further, if children learn patience and aspirations from their parents, changes in parents' preferences would have an impact not only on parents' decisions over children's schooling but also on children's own decisions. If children are more patient they may also, for example, aspire to jobs with better wages after a period of training or education, as opposed to lower paying jobs (Lawrance, 1991); be more likely to participate in the labor market and less likely to be on welfare as adults (Golsteyn et al., 2014); and invest more in human capital formation (Cadena and Keys, 2015). They may also choose to invest more in their own children. ${ }^{1}$

We identify three potential channels through with the program may affect time preferences and aspirations (while acknowledging that differentiating between these channels is beyond the scope of this paper). First, in the context of Familias en Acción (and as is common in many CCTs), participant households have to take their children to medical check-ups and send their children to school in order to receive the monetary transfer. These conditions "force" them to change their behaviour and invest in the future and delay present consumption. With time, this changed behaviour might create the habit of delaying consumption, Carvalho et al. (2016). That is, it may develop a greater taste for education and hence higher educational aspirations. It may also change deeper preference parameters, specifically time preferences.

Second, the increase in income due to the monetary transfers may allow recipient households to consider a wider range of options for themselves and their children. Once households are living above subsistence levels they can contemplate delaying consumption, investing (in education or productive activities, for example), and planning present-consumption versus future-

\footnotetext{
${ }^{1}$ Dohmen et al. (2012); Volland (2013); Zumbuehl et al. (2013); and Black et al. (2015) provide empirical evidence of intergenerational transmission of attitudes (risk, trust, leisure activities) from parents (and other role models) to children. Further Macours and Vakis (2014), Chiapa et al. (2012) and Black et al. (2015) provide evidence that attitudes and aspirations are determined by environmental factors, experiences and interactions with others.
} 
consumption. $^{2}$ This again could impact educational aspirations and time preferences affecting many different facets of people's lives.

Finally, the program requires caregivers to attend educational talks. These information sessions may change preferences by introducing parents to new ideas, Becker and Mulligan (1997). The information parents receive in the educational talks may create awareness of the importance of education, nutrition, health and general child care, and hence change their preferences for human capital investment. Interactions with the educated professionals in medical centres when taking children to the check-ups may also alter people's view of the world, and hence preferences, Chiapa et al. (2012).

Although time preferences are often assumed to be immutable by economists, a considerable body of evidence suggests that time preferences can be affected by numerous factors, such as parental teaching, social pressure, living in poverty and income shocks. ${ }^{3}$ Empirical evidence of the evolution of preferences is however relatively limited, partly due to the lack of longitudinal data. Kirby et al. (2002), using information on time preferences from incentivized choices of immediate or delayed gains every three months for two years in rural Bolivia, find that time preferences (and high rates of consumption and impulsive behaviour) are influenced by situational factors like income variation. Dean and Sautmann (2014) use data on individuals in Mali over a period of seven weeks and find that the marginal rate of intertemporal substitution varies systematically with income, consumption, spending shocks and savings. Carvalho et al. (2016) find that opening a savings account increases the willingness to delay gratification among poor households in Nepal. Providing financial education to randomly selected high school students was found to decrease present bias, Lührmann et al. (2015). ${ }^{4}$ Several studies also show that interactions with others can influence time preferences (Becker and Mulligan (1997); Bowles (1998)). Thus it does not seem unlikely that the income transfers, enforced

\footnotetext{
${ }^{2}$ Living in poverty has been shown to be associated with high time preferences (impatience) and low educational attainment. See Bauer and Chytilová (2010), Bauer and Chytilová (2013); Becker and Mulligan (1997); Kirby et al. (2002); Lawrance (1991).

${ }^{3}$ Parental influence is one of the earliest and most important sources of preference formation. Intergenerational transmission of behavioral preferences has been demonstrated for work attitudes (Fernandez and Fogli, 2009); leisure activities (Volland, 2013); and underlying preferences like risk and trust (Dohmen et al. (2012); Zumbuehl et al. (2013)) or academic aspirations and motivation (Benner and Mistry (2007); Kirk et al. (2011)). Time preferences have also been found to be associated with many factors, including education, wealth, income, poverty (Lawrance (1991) and Carvalho (2010)), gender and age (Bauer and Chytilová (2013), Anderson et al. (2004) and Rubalcava et al. (2009)).

${ }^{4}$ Several studies have also shown that risk preferences may change as a result of circumstances. For example, Cameron and Shah (2015) find that exposure to negative shocks in the form of natural disasters in Indonesia results in individuals making more risk-averse choices. See also studies cited in Chuang and Schechter (2015).
} 
conditions, information on the benefits of education and the exposure to educated professionals that are part of many CCTs may result in preference change.

In this paper we examine time preferences and child caregiver reports of educational aspirations for the child. We view educational aspirations as being a direct indicator of time preference change, in the context of household education decisions. Educational aspirations are important as they have been found to be a strong determinant of children's ultimate educational attainment (Benner and Mistry (2007); Chiapa et al. (2012); Spera et al. (2009)). ${ }^{5}$

There are very few studies that examine the impact of CCTs on preferences. The studies most closely related to our are Handa et al. (2014) which finds that an unconditional cash transfer program in Kenya did not affect households' intertemporal choices and Chiapa et al. (2012) which finds that participation in the Mexican CCT Progresa is associated with an increase in educational aspirations of about a third of a school year. They examine the impacts in the short term (within the first year of participation) and explain this positive effect as coming from mandated exposure to educated professionals (doctors and nurses). They do not examine time preferences directly.

The paper proceeds as follows. Section 2 outlines the characteristics of Familias en Acción. Section 3 discusses the data and identification strategy. Section 4 lays out the econometric methodology and Section 5 discusses the results. Section 6 concludes.

\section{The program}

Following the trend in a large number of Latin-American countries, Colombia implemented Familias en Acción, a conditional cash transfer program for the poor in late 2001/early 2002. To participate municipalities had to i) have a population less than 100,000 and not be the principal town of the state; ii) have sufficient health and education infrastructure ${ }^{6}$; iii) have a bank branch; and iv) indicate interest through the local government which had to complete the

\footnotetext{
${ }^{5}$ Parental aspirations are influenced by people with whom parents interact and with the income and wealth of neighbors (Appadurai (2004); Ray (2006)) and parents having higher expectations of the financial returns to education; (Attanasio and Kaufmann (2014); Sosu (2014); Spera et al. (2009)).

${ }^{6}$ With sufficient medical facilities being determined by the number of doctors and nurses per inhabitant; projected number of doctor appointments; and the number of child check-ups the municipality is capable of administering. The educational indicators used were: student-teacher ratios, classroom area per student, dropout rates, and the growth of school fees.
} 
required documents and provide the identification numbers of the potential beneficiaries of the program. To be eligible, households had to be classified as poor by the poverty index (SISBEN); have at least one child aged between 0 and 17; and live in a participating municipality. Our empirical identification strategy will take advantage of the selection into the program on the basis of the poverty index.

The program commenced with 691 rural municipalities (out of a total of 1060 in the country). Ninety percent of eligible households participated. Due to the perceived success of the program with respect to health, nutrition and education outcomes, in 2007 it was extended to other municipalities, both rural and urban. ${ }^{7}$ The program grew from reaching about 320,000 households to around 2.8 million in approximately 900 municipalities in 2010, making Familias en Acción one of the biggest programs for poor households implemented by the Colombian government. The program has two components - a health and nutrition component and an educational component.

Health and Nutrition Component The health and nutrition component was offered to eligible households with at least one child aged between 0 and 6. Each household received approximately US\$25 regardless of the number of children they had in the 0 to 6 year age bracket. This transfer was conditional upon children attending growth and development checkups every two months, and a vaccination program. Primary caregivers were required to attend information sessions where topics such as child health care, nutrition, household sanitation and contraception were discussed. ${ }^{8}$

Educational Component The educational component was offered to eligible households with children aged between 7 and 17 . The transfer was approximately US $\$ 8$ for each child in primary school, and US\$16 for each child in secondary school. This transfer was conditional on average school attendance of more than $80 \%$.

\footnotetext{
${ }^{7}$ A quasi-experimental design was originally built into the implementation, with treatment municipalities receiving the program matched with control communities that didn't receive the program. By 2012, the year in which the time preference and educational aspirations data was collected, the program had however been extended to all municipalities, making it necessary to use regression discontinuity design to identify treatment effects, rather than difference-in-difference comparisons of treatment and control areas.

${ }^{8}$ The primary caregiver is normally the mother of the child receiving the transfer. If the mother does not live in the household (about $6 \%$ of cases), the father, the grandmother or other household members can be the recipient primary caregiver.
} 
On average the transfers (in total, across both components of the program) accounted for approximately $20 \%$ of household income.

The SISBEN index was designed by the government to rank households and identify a target population for social expenditure. It is a proxy indicator of household resources and ranges in value from 0 to 100. Values close to 0 represent the poorest households while those close to 100 the richest. Different poverty thresholds were used for program eligibility in urban and rural areas. To be eligible urban households were required to have a SISBEN score lower than 34 and rural households a score lower than $14 .^{9}$

\section{Data and Methods}

\subsection{Data}

The data used in this paper come from a survey implemented in 2012, 10 years after the program started. The sample consists of households which were both eligible and ineligible for the program at its commencement in late 2001/early 2002. ${ }^{10}$ In urban (rural) areas the sample consists of eligible households with a SISBEN score in the range of 0 and 34 (0 and 14) and ineligible households with a score between 34 and 40 (14 and 18).

The survey provides a wide range of data including information on socio-demographic charac-

\footnotetext{
${ }^{9}$ The SISBEN score is constructed as the first principal component of four factors of household characteristics reflecting education and social security; demographic characteristics and income; dwelling quality; and available utilities. Eligibility is based on being SISBEN Level 1. The threshold to be classified in that level is lower in rural than in urban areas as the standard of living is generally lower in rural areas. If the threshold was the same in rural and urban areas, most households in rural areas would be classified as poor.

The SISBEN score is also used for targeting of subsidized health care and a children's nursery program. The threshold for both of these programs is higher than that for all of the households in our sample. Thus, we are confident that we are identifying the effect of Familias en Acción not other targeted programs.

${ }^{10}$ The sample was constructed by tracking eligible households in the original participating regions which were in the 2002 baseline sample. (The program commenced in late 2001 in only a small number of regions, in most regions it started after the baseline survey was implemented.) A random sample of $66 \%$ of these original baseline households was selected to be tracked and form part of the 2012 survey. The 2012 survey managed to track $60 \%$ of these households. Households that could not be located were replaced by other randomly selected eligible households in the baseline survey. The resultant sample of eligible households was then appended with households which were ineligible at baseline but had SISBEN scores close to the cut-off (within four SISBEN points in rural areas and six points in urban areas) as identified and tracked from the original 1999 government census of households which was used to generate SISBEN scores and determine eligibility. The total number of households interviewed was 7550 - 5718 eligible and 1832 ineligible. A greater range of SISBEN scores was allowed in urban areas to ensure a sufficiently large urban sample (as in urban areas people move around more and so are harder to track.) The target number of ineligible households was smaller than for eligible households and was determined on the basis of providing sufficient power for comparisons between the two groups.
} 
teristics, children's schooling history and most importantly for this paper, time preferences and caregivers' aspirations for their children's schooling attainment. ${ }^{11}$ Time preferences are elicited from a set of four questions offering the (hypothetical) choice of receiving money now or a larger sum of money in a future period. These questions were asked of one adult per household (normally the household head or his/her spouse). ${ }^{12}$ Table 1 presents the four choices. The respondent is first asked to choose between receiving 100,000 Colombian pesos today (approximately U\$55, or about $12 \%$ of average monthly income) and 105,000 pesos in a month (U\$58). If the person chooses the 105,000 pesos in a month's time the questions cease. If however, 100,000 pesos today is chosen, the respondent is then asked to choose between 100,000 pesos today and 120,000 pesos in a month's time (U\$66). This process continues with the amount being offered in a month's time increasing to 150,000 pesos $(\mathrm{U} \$ 82)$ and then 200,000 pesos ( $\mathrm{U} \$ 110)$ if the amount today continues to be chosen. Table 1 shows the correspondence between the choices and the implied discount rate. ${ }^{13}$ A low discount rate represents a low preference for present consumption and we will refer to this interchangeably as low time preferences or greater patience. In our empirical analysis we follow Bauer and Chytilová (2010) and use a midpoint of the interval as our best estimate of the person's discount rate. Given that the last interval is open to the right (1 $\infty)$, for that case we use the lower value of the interval. This gives us the lower bound of the real discount rate for this sample. Thus we have five possible underlying discount rates: 0.025 , $0.125,0.350,0.75$ and 1.

Figure 1 shows the distribution of the choices made by our sample of respondents. The most frequently chosen option ( $46 \%$ of respondents) is to always choose 100,000 pesos today i.e. the most impatient option, corresponding to a discount rate between one and infinity. This is consistent with Rubalcava et al. (2009) in rural Mexico where $52 \%$ of adults selected the most impatient option. Chuang and Schechter (2015) also find high levels of impatience in Paraguay. The median monthly discount rate for our sample is 0.75 which means that $\$ 100$ today is willingly given up in return for $\$ 175$ in one month.

\footnotetext{
${ }^{11}$ Although in total four waves of data were collected - in 2002 (baseline), 2003, 2006 and 2012 - the time preference and educational aspirations data were only collected in the 2012 wave so we utilize only this wave here.

${ }^{12}$ Chuang and Schechter (2015) find that hypothetical questions of this sort elicit relatively reliable measures of time preferences, in that they are significantly correlated over time (more so than risk preferences elicited from widely used incentivized experiments). Note that the person responding to the time preference questions is only the caregiver in $24 \%$ of cases. If we re-estimate the time preference models below using only the time preference data reported by caregivers, the results are unaffected.

${ }^{13}$ The implied discount rate, $\delta$, equates the value of $\$$ A today with the value of $\$ \mathrm{~B}$ in a month: $\delta=\frac{B-A}{A}$. For example, if a person is presented with a choice of $\$ 100$ today or $\$ 105$ in a month and the person chooses $\$ 105$ in a month, the implied discount rate is at least 5 percent per month.
} 
All caregivers of the oldest child under 18 years of age in the household are asked about their educational aspirations for this particular child. We examine program impact on two measures of educational aspirations - the caregivers' reported probability of the child completing secondary education by age 18; and the probability that s/he will ever graduate with a tertiary education. ${ }^{14}$ The average probability that the child finishes secondary education by age 18 reported by caregivers is $80 \%$ in rural areas and $83 \%$ in urban areas. The aspirations for completion of tertiary education are $60.5 \%$ in rural areas and $69.4 \%$ in urban areas.

A comparison of the reported expectations data with actual educational outcomes over the course of the program reveals that these expectations are in excess of actual outcomes. Using the endline data for the ineligible sample (so as to avoid contamination by program impact), we find that $45 \%$ actually completed secondary school in rural areas and $68 \%$ in urban areas. Completion of a tertiary education is not reported in the data but in rural areas only $19 \%$ obtained some tertiary education and $29 \%$ in urban areas.

\section{Econometric framework}

\subsection{Identification strategy}

The causal treatment effect on a potential outcome $\left(Y_{i}\right)$ is the difference between the outcome when exposed to the program $Y_{i}(1)$ and the outcome without exposure to the program $Y_{i}(0)$. The problem in causal inference is that we do not observe both states at the same time, we only observe the outcome related to the treatment received by the household. If we define $D_{i} \in\{0,1\}$ where $D_{i}=0$ denotes non-participation and $D_{i}=1$ participation in the program,

$$
Y_{i}=\left(1-D_{i}\right) Y_{i}(0)+D_{i} Y_{i}(1)= \begin{cases}Y_{i}(0) & \text { if } D_{i}=0 \\ Y_{i}(1) & \text { if } D_{i}=1\end{cases}
$$

The problem thus lies in constructing an appropriate counterfactual that captures the likely outcome in the different treatment state. RD designs exploit the fact that the probability of

\footnotetext{
${ }^{14}$ The questions used to elicit these probabilities are (i) By the time the child is 18 years old what is the probability he/she will have completed secondary education? In Spanish, "¿Qué tan posible es que el menor, cuando tenga 18 años, haya terminado el bachillerato completo?"; (ii) What is the probability that he/she will graduate from tertiary education? In Spanish, "¿Qué tan posible es que el menor se gradúe de educación superior?”. Only around $10 \%$ of the caregivers are people other than the mother or father of the child.
} 
participation in the treatment changes discontinuously in a continuous covariate $Z_{i}$, so that households lying just above a fixed threshold $c$ are similar to households that are just below, with the only difference being that the former do not participate in the program while the latter do. A comparison of ineligible households on one side of the cut-off and eligible households on the other side thus allows us to estimate the causal effect of the program free of selection bias. ${ }^{15}$ In this paper we use a regression discontinuity design that exploits the discontinuity in program eligibility around the SISBEN poverty index cut-off score to identify the program impact. The key point for our identification strategy is that participation in the program was determined (at least partially) by whether the SISBEN poverty score lies above or below the program cut-off and hence there is a discontinuity in program participation at the cut-off point.

Household participation can be written as:

$$
D_{i}\left(Z_{i}\right)=I\left[Z_{i} \leq c\right]
$$

In the case of complete compliance, the value of $D_{i}$ is a deterministic function of $Z_{i}$ and the probability of participation jumps from 0 to 1 at the threshold. As shall be seen below, our context is one of incomplete compliance so we use a fuzzy RD design. In this case:

$$
\lim _{z \downarrow c} \operatorname{Pr}\left(D_{i}=1 \mid Z_{i}=z\right) \neq \lim _{z \uparrow c} \operatorname{Pr}\left(D_{i}=1 \mid Z_{i}=z\right)
$$

where $\lim _{z \downarrow c} \operatorname{Pr}\left(D_{i}=1 \mid Z_{i}=z\right)$ is the limit of the probability of participation when the value of $z$ approaches $c$ from the right and $\lim _{z \uparrow c} \operatorname{Pr}\left(D_{i}=1 \mid Z_{i}=z\right)$ as $z$ approaches $c$ from the left. The average causal effect of the treatment is obtained from the ratio of the discontinuity in the outcome to the discontinuity in the participation at the eligibility threshold, Hahn et al. (2001).

$$
\tau=\frac{\lim _{z \downarrow c} E(Y \mid Z=z)-\lim _{z \uparrow c} E(Y \mid Z=z)}{\lim _{z \downarrow c} E(D \mid Z=z)-\lim _{z \uparrow c} E(D \mid Z=z)}
$$

This estimator implicitly weights the observations by the distance from the cut-off, hence producing a Local Average Treatment Effect (LATE) evaluated at the cut-off for eligibility. As discussed in Imbens and Angrist (1994), in order to interpret this ratio as a causal effect we

\footnotetext{
${ }^{15} Z_{i}$ could be itself associated with the potential outcomes but this association is assumed to be smooth. A detailed explanation of RD design can be found in Imbens and Lemieux (2008) and Lee and Lemieux (2010)
} 
need to assume monotonicity and excludability in the program participation function. Although monotonicity is not verifiable, it appears a reasonable assumption. In this context monotonicity implies that household participation in the program is a monotonically decreasing function of the poverty score so households which choose to participate when they are ineligible are assumed to still choose to participate if they became eligible. Excludability requires that being at either side of the cut-off point does not have an impact on individuals' discount rates or educational aspirations for their children except through participation in the program.

\subsection{Estimation equation}

We estimate the LATE using two stage least squares. We use a flexible parametric model to estimate the effect of program participation $D_{i}$ on $Y_{i}$ (time preferences or educational aspirations), instrumenting for $D_{i}$ with a dummy for eligibility in the program based on the household poverty score, $E_{i}$. The probability of treatment is:

$$
\operatorname{Prob}(D=1 \mid Z=z)=\gamma+\alpha E+g_{D}(z-c)
$$

where $E=1[Z \leq c]$ indicates program eligibility. We center the poverty score $Z_{i}$ to zero at the cut-off (hence $c$ to zero). ${ }^{16}$ The function $g_{D}(z-c)$ indicates a flexible polynomial regression function of order $p$ that allows the slope to be different to the left $\left(\beta_{l}\right)$ and the right $\left(\beta_{r}\right)$ of the threshold. The first and second stage estimation equations are (respectively):

$$
\begin{aligned}
& Y_{i}=\gamma_{1}+\tau D_{i}+E_{i} \sum_{p=1}^{P} \beta_{l p} Z_{i}^{p}+\left(1-E_{i}\right) \sum_{p=1}^{P} \beta_{r p} Z_{i}^{p}+\varepsilon_{i h} \\
& D_{i}=\gamma_{2}+\alpha E_{i}+E_{i} \sum_{p=1}^{P} \beta_{l p} Z_{i}^{p}+\left(1-E_{i}\right) \sum_{p=1}^{P} \beta_{r p} Z_{i}^{p}+v_{i h}
\end{aligned}
$$

The causal impact is captured by $\tau$. We expect the program to reduce time preferences, in which case $\tau$ would be negative and to increase educational aspirations, in which case, $\tau$ would

\footnotetext{
${ }^{16}$ For the analysis hereafter we centre the poverty score at zero with negative scores representing poverty scores less than the cut-off (sufficiently poor to be eligible) and positive scores representing ineligibility. Centering the score to zero also allows us to undertake a combined analysis of the total sample even though the cut-off point for eligibility was different in rural and urban areas. However, as urban and rural areas differ in a variety of ways, not least in terms of the level of demand for education, we also break down the analysis by urban/rural.
} 
be positive. In estimations with the caregiver as the unit of observation we cluster the error terms in both equations at the household level as the poverty score is calculated at that level.

The use of an incorrect functional form can result in biased estimates of program impact. We test functional forms of different polynomial order against each other using the cross-validation procedure suggested by Lee and Lemieux (2010) based on the Akaike information criterion (AIC). Assuming that the resulting empirical specification is the true functional form of the underlying data, the LATE provides an efficient estimator of the treatment effect. ${ }^{17}$

\section{Results}

This section begins with a visual inspection and formal test of discontinuity in program participation at the SISBEN cut-off score. We then present tests of the continuity of the poverty index at the cut-off and a presentation of some evidence of local balance of baseline variables on both sides of the cut-off. The results from the first stage and the tests of the different polynomial orders are then presented before proceeding to the estimated causal treatment effects. We conduct some further tests of the econometric specification before concluding.

\subsection{Discontinuity in participation at the poverty score cut-off}

Figure 2 graphs the probability of program participation by poverty score. A clear jump of about $35 \%$ in the probability of participation in Familias en Acción is visible around the eligibility cut-off point (poverty score equal to zero). ${ }^{18}$ Table A1 in the appendix presents the results of formally testing the significance of the discontinuity. It presents the size of the discontinuities in the probability of program participation for models using different polynomial orders. ${ }^{19}$ This

\footnotetext{
${ }^{17}$ The preferred specification is the one with the lowest AIC. We allow for flexibility in the model by also estimating different polynomial orders at each side of the cut-off but in most cases the preferred specification has the same polynomial order at both sides of the cut-off. We also conducted a sensitivity test where we estimated the program impact using the second-best specification according to the AIC. The results are similar but less precisely estimated. The Bayesian Information Criterion (BIC) is an alternative selection criteria for optimal polynomial order. The results are robust to using the BIC criteria. Results available on request.

${ }^{18}$ To allow us to focus on the area around the cut-off, all the visual inspections are hereafter truncated to the poverty score interval $[-4,4]$. The full sample used for estimation spans the range from -14 to 4 for rural areas and -34 to 6 in urban areas. Figure 2 is constructed for the sample of households for which we have discount rates i.e. one observation per household head. A discontinuity of similar magnitude can also be seen for the educational aspirations sample i.e. one observation per caregiver, and when disaggregated by urban and rural status. Figures available on request.

${ }^{19}$ Panel A of table A1 presents the results for the time preferences sample (one observation per household. Panels B presents the analogous results for the sample with one observation per caregiver. These are the first
} 
is the estimate of $\alpha$ (the impact of eligibility on participation) in equation (7). Using the preferred specification program eligibility is associated with an increase of $47 \%$ in the probability of participation in Familias en Acción (44\% in rural areas and $51 \%$ in urban areas). ${ }^{20}$ The parameter is in all cases strongly significant.

\subsection{Continuity in the poverty score}

An important condition required for the RD design to provide unbiased causal estimates is that households cannot (precisely) manipulate their eligibility. That is, they cannot manipulate their poverty score so as to gain access to the program. Continuity in the poverty score at the threshold is evidence of absence of manipulation. We test this assumption in two ways. First, we use a visual inspection of the continuity on the density of the poverty score around the cut-off. Figure 3 shows the density of the poverty score is continuous at the threshold for eligibility.

To more formally test if there is continuity in the number of respondents on each side of the threshold, we use OLS to regress the counts in bins of size 0.05 from -1.5 to 1.5 in the poverty score on eligibility, McCrary (2008). Results are presented in Table 2. We find that the difference in the number of respondents is not statistically significant in the aggregated sample or in rural or urban areas. Hence, it is unlikely that manipulation is biasing our results.

\subsection{Baseline covariates}

A further important assumption needed in order to identify the program impact is that individuals to the left and right of the cut-off are otherwise similar. We would thus expect to find no discontinuities in baseline characteristics of households at the program eligibility cut-off. We however do not have information at the baseline for individuals above the cut-off (because ineligible households were not part of the original baseline sample). Comparing covariates at the endline could simply reflect the program impact on these variables. Thus we examine the local balance on either side of the threshold for eligibility using only those endline variables that we consider unlikely to have been affected by the program - age and level of education of the

stage estimates for different polynomial order specifications. The size of the effect decreases only slightly as the polynomial order increases and remains strongly significant at the $1 \%$ level. Hence the results do not appear overly sensitive to choice of polynomial order.

${ }^{20}$ These are weighted probabilities (weighted by the distance from the threshold) and so differ from the unweighted probabilities shown in Figure 2. 
household head. If the RD design is valid, these characteristics should be continuous at the threshold. We estimate an RD design with these variables as the dependent variable. Results are presented in Table 3. We find no significant differences in both the rural and urban samples.

\subsection{Effect of program participation on time preferences and educational as- pirations}

Figure 4 presents a visual demonstration of the discontinuity in the expected value of time preferences and education expectations at the threshold for eligibility using the preferred polynomial order. There is no jump evident in the discount rate nor in the probability of finishing secondary school at the eligibility threshold. A jump at the threshold is apparent for the probability of completing higher education; however in the opposite of the anticipated direction. This result, if statistically significant, would suggest that program participation is having a negative effect on tertiary education aspirations. Similar results are found for both rural and urban areas (Figures $\mathrm{A} 1$ and $\mathrm{A} 2)$.

The results of formal IV estimation of the causal impact of the program on time preferences and education aspirations are presented in Panel A of Table 4. In the time preferences models the coefficient on eligibility is negative, indicating an increase in patience, but statistically insignificant for the whole sample and separately in rural and urban areas (smallest p-value $=0.540)$. The point estimates are also small in magnitude. A $0.015(2.0 \%)$ reduction in the discount factor or 0.04 standard deviations over the whole sample. These findings are consistent with the null effect for this sample found in Figure 4 and suggest no program impact on time preferences.

We also do not find the anticipated positive effect on educational aspirations. Table 4 shows that the estimated effects are insignificant except for a negative and strongly significant effect on the probability of the child finishing higher education $(\mathrm{p}=0.02)$. This suggests that participating in the program has no effect on aspirations for the completion of secondary school but is associated with a 14.3 percentage point decrease in the perceived probability of finishing higher education. While non-participating caregivers on average attach a $76 \%$ probability to their children completing higher education, participating caregivers on average report a probability of $62 \%$. This negative impact is found in both urban and rural areas but is only significant for urban areas. 
This finding is the opposite of what was expected. It is consistent with participating households coming to see their children's schooling attainment as being dependent on program support, and as the program is known to finish on completion of secondary school (age 18) they attach a lower probability to being able to continue than those households who have not been exposed to the program. It also underscores the role of the conditions in improving educational attendance for children who presumably would not otherwise have completed secondary school.

The inclusion of additional covariates in the RD design estimation can increase the precision of the estimates (Imbens and Lemieux (2008); Lee and Lemieux (2010)). Panel B of Table 4 presents the results for each outcome and the coefficient from the first stage of eligibility on participation when we include controls for gender, age, years of education and the region (rural or urban) of the respondent. The inclusion of the covariates does not affect the results. The poverty score continues to be a strong determinant of program participation. The program impact on time preferences and the reported probability of completing secondary education remains insignificant. For the probability of finishing tertiary education, the program effect is of a smaller magnitude but still negative and statistically significant across the whole sample and in urban areas. $^{21}$

In summary, we find no evidence that time preferences change with exposure to the program. We also find no effect on the aspirations of caregivers for their children's education measured by the probability of finishing secondary school. We find, however, a negative program effect on the perceived probability that children will finish higher education. ${ }^{22}$

\footnotetext{
${ }^{21}$ The coefficients on the new covariates are largely consistent with the existing literature on time preferences, validating our time preference measure. We find that women are more patient than men. Individuals living in urban areas exhibit less patience. Age and education are not significantly associated with time preferences in our sample. This is likely a consequence of the low variation in the sample as the population is relatively poor, education is low and because all households are required to have children aged 0 to 17 , the age of household heads/spouses is similar. Parents' years of education is an important determinant of educational aspirations for their children.

${ }^{22}$ We also estimated the educational aspirations specifications restricting the sample to reports by mothers. As mothers are the ones who attend the program information sessions, they are the most likely to have their aspirations changed by the program. The results for mothers are however similar to those obtained for the whole sample of caregivers. Results available on request.

We also estimated the program effect using non-parametric regression discontinuity following Calonico et al. (2014) The results are similar and are reported in Tables A2 to A4 in the Appendix.
} 


\subsection{Time preferences and current income transfer}

The treatment group contains households who were participating in the program at the time of the interview and also those who had participated in the past. It is possible that time preferences are affected by the receipt of the cash transfer during the period in which the transfer is received, but revert to the original preferences once the cash transfer is no longer received. This could happen as additional income diminishes the pressure for present consumption and allows households to delay consumption and plan better (Becker and Mulligan (1997); Carvalho (2010); Kirby et al. (2002); Tanaka et al. (2006)). The effect on current participants' preferences may be being masked by the inclusion of households that participated in the program in the past but are no longer receiving the extra income (program impacts may also decrease over time). To explore this we disaggregate the sample into those households currently receiving the transfer and those that have received it in the past but are no longer recipients because they no longer have children aged 0 to 17 in the household. Panel A in Table 5 presents the results. All impacts are insignificant in both samples.

For those households which are receiving transfers at endline, we can also investigate whether the increase in consumption that the transfers afford directly affects preferences. We do this by adding endline household per capita consumption as an additional control variable. The results are presented in Panel B of Table 5 and are qualitatively unaffected.

In unreported results we also examine the effect of different length of exposure to the program by including a variable reflecting years of exposure to the program. This variable is insignificant and the results stand.

\section{Conclusions}

In conclusion, we find that the program had no impact on participants' time preferences. We also find no evidence that the program increases caregivers' educational aspirations for their children. Unexpectedly, we systematically find that program participation is associated with parents attaching a lower probability to their children finishing tertiary education, particularly in urban areas. These results suggest that participant households' motivation for sending their children to school is a direct result of the monetary transfer they received and the accompanying 
conditions rather than to any underlying changes in preferences and aspirations. The results for tertiary education further suggest that households may come to depend on the transfers to educate their children, resulting in lowered educational aspirations once the program ends (when their children are at the age to embark on tertiary education).

From a policy perspective, the inability of the program to change people's preferences so they are more prepared to delay present consumption in the interest of investment in the future and, more specifically, actively desire their children to gain more education, means that programs of this sort require ongoing financial incentives in order to generate the impacts on human capital. If the transfers were to stop, program benefits would be limited to those associated with the educational and health improvements that were obtained during the program's implementation (which may be substantial) and the health and education of subsequent children would likely revert to pre-program levels. ${ }^{23}$

Finally, the benefits of such programs do not extend to the wide array of potential benefits arising from a greater ability to make decisions that require an investment today in order to reap future returns

\footnotetext{
${ }^{23}$ Visaria et al. (2016) find that school attendance was unchanged or negatively impacted for some children after the withdrawal of a CCT program in Indian slums (relative to baseline levels). Baird et al. (2016) find that for women participating in Malawi's cash transfer programs, gains in empowerment and marriage outcomes were reversed two years after the program stopped and there was no effect on health or labour market outcomes. The findings of these studies are consistent with our results.
} 


\section{Acknowledgements}

We thank Oriana Bandiera and participants at the 2016 Italian Summer School in Development Economics, 2015 Australasian Development Economics Workshop and the 2015 Workshop on Emerging Economies at the University of New South Wales for their comments. We are grateful to Orazio Attanasio, the Colombian National Planning Department, Econometria, and the Institute of Fiscal Studies for providing access to the data and for allowing us to participate in the long term evaluation of Familias en Acción. Any errors are ours alone. 


\section{References}

Anderson, C. L., M. Dietz, A. Gordon, and M. Klawitter, "Discount Rates in Vietnam," Economic Development and Cultural Change, 2004, 52 (4), 873-887.

Appadurai, A., "The Capacity to Aspire: Culture and the Terms of Recognition," in V. Rao and M. Walton, eds., Culture and Public Action, Stanford University Press, Stanford Social Sciences, 2004, pp. 59-84.

Attanasio, O. and K. Kaufmann, "Educational Choices, Subjective Expectations, and Credit Constraints," NBER Working Paper, 2009, (15087).

_ and _ , "Education choices and returns to schooling: Mothers' and youths' subjective expectations and their role by gender," Journal of Development Economics, 2014, 109 (0), 203-216.

_ , E. Battistin, and A. Mesnard, "Food and Cash Transfers: Evidence from Colombia," Economic Journal, 2012, 122 (559), 92-124.

Attanasio, O O., E. Fitzsimons, A. Gomez, M.I. Gutierrez, C. Meghir, and A. Mesnard, "Children's Schooling and Work in the Presence of a Conditional Cash Transfer Program in Rural Colombia," Economic Development and Cultural Change, 2010, 58 (2), 181-210.

Attanasio, Orazio, Erich Battistin, Emla Fitzsimons, and Marcos Vera-Hernandez, "How effective are conditional cash transfers? Evidence from Colombia," 2005.

Baez, J.E. and A. Camacho, "Assessing the long-term effects of conditional cash transfers on human capital: evidence from Colombia," The World Bank, Policy Research Working Paper Series: 5681, 2011.

Baird, Sarah, Craig McIntosh, and Berk Özler, "When the money runs out: Do cash transfers have sustained effects?," 2016.

_, Francisco HG Ferreira, Berk Özler, and Michael Woolcock, "Conditional, unconditional and everything in between: a systematic review of the effects of cash transfer programmes on schooling outcomes," Journal of Development Effectiveness, 2014, 6 (1), 1-43.

Basu, K., Global labor standards and local freedoms, UNU World Institute for Development Economics Research., 2003.

Bauer, M. and J. Chytilová, "The Impact of Education on Subjective Discount Rate in Ugandan Villages," Economic Development and Cultural Change, 2010, 58 (4), 643-669.

_ and _, "Women, Children and Patience: Experimental Evidence from Indian Villages," Review of Development Economics, 2013, 17 (4), 662-675.

Becker, G. S. and Mulligan, "The endogenous determination of time preference," Quarterly Journal of Economics, 1997, 112 (3), 729-758.

Benner, A. D. and R. S. Mistry, "Congruence of mother and teacher educational expectations and low-income youth's academic competence," Journal of Educational Psychology, 2007, 99 (1), 140.

Black, S. E., P. J. Devereux, P. Lundborg, and K. Majlesi, "On the Origins of Risk-Taking," National Bureau of Economic Research, 2015, (w21332).

Bowles, S., "Endogenous preferences: The cultural consequences of markets and other economic institutions," Journal of economic literature, 1998, pp. 75-111.

Cadena, Brian C and Benjamin J Keys, "Human capital and the lifetime costs of impatience," American Economic Journal: Economic Policy, 2015, 7 (3), 126-153. 
Calonico, Sebastian, Matias D Cattaneo, and Rocio Titiunik, "Robust Nonparametric Confidence Intervals for Regression-Discontinuity Designs," Econometrica, 2014, 82 (6), 2295-2326.

Cameron, Lisa and Manisha Shah, "Risk-taking behavior in the wake of natural disasters," Journal of Human Resources, 2015, 50 (2), 484-515.

Carvalho, L., S. Prina, and J. Sydnor, "The effect of savings on risk attitudes and intertemporal choices," Journal of Development Economics, 2016, 120, 41-52.

Carvalho, Leandro S, "Poverty and time preference," 2010.

Chiapa, Carlos, José Luis Garrido, and Silvia Prina, "The effect of social programs and exposure to professionals on the educational aspirations of the poor," Economics of Education Review, 2012, 31 (5), 778-798.

Chuang, Yating and Laura Schechter, "Stability of experimental and survey measures of risk, time, and social preferences: A review and some new results," Journal of Development Economics, 2015, 117, 151-170.

Das, Jishnu, Quy-Toan Do, and Berk Özler, "Reassessing conditional cash transfer programs," The World Bank Research Observer, 2005, 20 (1), 57-80.

Das, M., "Persistent inequality: An explanation based on limited parental altruism," Journal of Development Economics, 2007, 84 (1), 251-270.

Dean, Mark and Anja Sautmann, "Credit constraints and the measurement of time preferences," Available at SSRN 2423951, 2014.

Dohmen, T., A. Falk, D. Huffman, and U. Sunde, "The Intergenerational Transmission of Risk and Trust Attitudes.," Review of Economic Studies, 2012, 79 (2), 645-677.

Edmonds, Eric V, "Child labor," Handbook of development economics, 2007, 4, 3607-3709.

Fernandez, Raquel and Alessandra Fogli, "Culture: An empirical investigation of beliefs, work, and fertility," American Economic Journal: Macroeconomics, 2009, 1 (1), 146-177.

Fiszbein, A., N. R. Schady, and F. H. Ferreira, Conditional cash transfers: reducing present and future poverty, World Bank Publications, 2009.

Golsteyn, Bart HH, Hans Grönqvist, and Lena Lindahl, "Adolescent time preferences predict lifetime outcomes," The Economic Journal, 2014, 124 (580), F739-F761.

Hahn, Jinyong, Petra Todd, and Wilbert Van der Klaauw, "Identification and estimation of treatment effects with a regression-discontinuity design," Econometrica, 2001, 69 (1), 201-209.

Handa, Sudhanshu, Bruno Martorano, Carolyn Halpern, Audrey Pettifor, and Harsha Thirumurthy, "Subjective Well-being, Risk Perceptions and Time Discounting: Evidence from a Large-Scale Cash Transfer Programme," Technical Report, Innocenti Working Paper 2014.

Imbens, Guido and Karthik Kalyanaraman, "Optimal bandwidth choice for the regression discontinuity estimator," The Review of economic studies, 2011, p. rdr043.

Imbens, Guido W and Joshua D Angrist, "Identification and estimation of local average treatment effects," Econometrica, 1994, 62 (2), 467-475.

_ and Thomas Lemieux, "Regression discontinuity designs: A guide to practice," Journal of econometrics, 2008, 142 (2), 615-635. 
Janvry, Alain De and Elisabeth Sadoulet, "Conditional cash transfer programs for child human capital development: Lessons derived from experience in Mexico and Brazil," in "presentation at the GRADE 25th Anniversary Conference,Investigación, Politicas y Desarrollo, Lima, Peru" 2005.

Jensen, R., "The (Perceived) Returns to Education and the Demand for Schooling," Quarterly Journal of Economics, 2010, 125 (2), 515-548.

Kirby, K. N., R. Godoy, V. Reyes-Garcia, E. Byron, L. Apaza, W. Leonard, . .., and D. Wilkie, "Correlates of delay-discount rates: Evidence from Tsimane' Amerindians of the Bolivian rain forest," Journal of Economic Psychology, 2002, 23 (3), 291-316.

Kirk, Chris Michael, Rhonda K Lewis-Moss, Corinne Nilsen, and Deltha Q Colvin, "The role of parent expectations on adolescent educational aspirations," Educational Studies, 2011, 37 (1), 89-99.

Lawrance, E. C., "Poverty and the rate of time preference: evidence from panel data," Journal of Political Economy, 1991, pp. 54-77.

Lee, David S and Thomas Lemieux, "Regression discontinuity designs in economics," Journal of economic literature, 2010, 48 (2), 281-355.

Lührmann, Melanie, Marta Serra-Garcia, and Joachim Winter, "Teaching teenagers in finance: does it work?," Journal of Banking \& Finance, 2015, 54, 160-174.

Macours, Karen and Renos Vakis, "Changing Households' Investment Behaviour through Social Interactions with Local Leaders: Evidence from a Randomised Transfer Programme," The Economic Journal, 2014, 124 (576), 607-633.

McCrary, Justin, "Manipulation of the running variable in the regression discontinuity design: A density test," Journal of Econometrics, 2008, 142 (2), 698-714.

Ray, Debraj, "Aspirations, poverty, and economic change," Understanding poverty, 2006, pp. 409-421.

Rubalcava, Luis, Graciela Teruel, and Duncan Thomas, "Investments, time preferences and public transfers paid to women," Economic Development and cultural change, 2009, 57 (3), 507.

Sosu, Edward M, "Predicting maternal aspirations for their children's education: The role of parental and child characteristics," International Journal of Educational Research, 2014, 67, 67-79.

Spera, Christopher, Kathryn R Wentzel, and Holly C Matto, "Parental aspirations for their childrens educational attainment: Relations to ethnicity, parental education, childrens academic performance, and parental perceptions of school climate," Journal of Youth and Adolescence, 2009, 38 (8), 1140-1152.

Tanaka, Tomomi, Colin F Camerer, and Quang Nguyen, "Poverty, politics, and preferences: Field experiments and survey data from Vietnam," 2006.

Visaria, Sujata, Rajeev Dehejia, Melody M. Chao, and Anirban Mukhopadhyay, "Unintended Consequences of Rewards for Student Attendance Results from a Frield Experiment in Indian Classrooms," NBER Working Paper, 2016, (22528), 1-31.

Volland, B., "On the intergenerational transmission of preferences," Journal of Bioeconomics, 2013, 15 (3), 217-249.

Zumbuehl, M., T. Dohmen, and G. Pfann, "Parental investment and the intergenerational transmission of economic preferences and attitudes," SOEP papers on Multidisciplinary Panel Data Research, 2013. 


\section{Tables}

Table 1: Time Preference Choices

\begin{tabular}{ccccccc}
\hline & & & & & & \\
& Option A & Option B & Choice & Implied Discount Rate Range & Mid point used & Time preference \\
\hline & & & & & & \\
1 & 100000 & 105000 & B & $0-0.05$ & 0.025 & high (most patient) \\
2 & 100000 & 120000 & $\mathrm{~B}$ & $0.05-0.2$ & 0.125 & \\
3 & 100000 & 150000 & $\mathrm{~B}$ & $0.2-0.5$ & 0.350 & \\
4 & 100000 & 200000 & $\mathrm{~B}$ & $0.5-1$ & 1 & low (most impatient) \\
5 & 100000 & 200000 & $\mathrm{~A}$ & $1-\infty$ & & \\
\hline
\end{tabular}

Table 2: Is there any evidence of manipulability of program eligibility?

\begin{tabular}{|c|c|c|c|}
\hline Dependent va & able $=$ No. & $\begin{array}{l}\text { ff observatic } \\
\text { Urban }\end{array}$ & $\begin{array}{c}\text { either side } \\
\text { Rural }\end{array}$ \\
\hline Eligibility & $\begin{array}{c}-0.0667 \\
(0.9491)\end{array}$ & $\begin{array}{c}0.7333 \\
(0.5465)\end{array}$ & $\begin{array}{c}-0.8000 \\
(0.7061))\end{array}$ \\
\hline Constant & $\begin{array}{c}8.7667^{* * * *} \\
(0.6711)\end{array}$ & $\begin{array}{c}3.2667^{* * * *} \\
(0.3865)\end{array}$ & $\begin{array}{c}5.5000^{* * *} * \\
(0.4993)\end{array}$ \\
\hline Observations & 60 & 60 & 60 \\
\hline R-squared & 0.0001 & 0.0301 & 0.0217 \\
\hline
\end{tabular}

Table 3: Discontinuities in Baseline Covariates around the Poverty Score Cut-off

\begin{tabular}{lcc}
\hline & & \\
& Rural & Urban \\
\hline \multirow{2}{*}{ Age of the household head } & 3.1518 & 1.8091 \\
Years of education of the household head & $(2.8880)$ & $(2.0944)$ \\
& $(0.5908$ & -0.5743 \\
& $(0.8868)$ \\
\hline
\end{tabular}

Notes: This table presents estimates of $\tau$ from the second stage of the IV estimation using the best fit polynomial specification. Household clustered standard errors in parentheses. $\mathrm{P}$ values in squared brackets. Significance: $* * * \mathrm{p}<0.01$, ** $\mathrm{p}<0.05$, * $\mathrm{p}<0.1$. 
Table 4: Effect of Program Participation on Time Preferences and Educational Aspirations

Panel A Panel B

All Rural Urban | All Rural Urban

\begin{tabular}{|c|c|c|c|c|c|c|}
\hline \multicolumn{7}{|l|}{ Time preferences } \\
\hline Discount Rate & $\begin{array}{l}-0.0148 \\
(0.0450) \\
{[0.7420]}\end{array}$ & $\begin{array}{l}-0.0252 \\
(0.0705) \\
{[0.7212]}\end{array}$ & $\begin{array}{l}-0.0355 \\
(0.0579) \\
{[0.5397]}\end{array}$ & $\begin{array}{l}-0.0136 \\
(0.0462) \\
{[0.7687]}\end{array}$ & $\begin{array}{l}-0.0234 \\
(0.0707) \\
{[0.7409]}\end{array}$ & $\begin{array}{l}-0.0620 \\
(0.0595) \\
{[0.2974]}\end{array}$ \\
\hline Female & & & & $\begin{array}{c}-0.0535 * * * \\
(0.0137)\end{array}$ & $\begin{array}{c}-0.0436^{* *} \\
(0.0198)\end{array}$ & $\begin{array}{c}-0.0674 * * * \\
(0.0190)\end{array}$ \\
\hline Age & & & & $\begin{array}{l}0.0010^{*} \\
(0.0006)\end{array}$ & $\begin{array}{c}0.0003 \\
(0.0009)\end{array}$ & $\begin{array}{c}0.0019^{* *} \\
(0.0008)\end{array}$ \\
\hline Years of education of caregiver & & & & $\begin{array}{l}-0.0023 \\
(0.0021)\end{array}$ & $\begin{array}{l}-0.0017 \\
(0.0032)\end{array}$ & $\begin{array}{l}-0.0031 \\
(0.0028)\end{array}$ \\
\hline Lives in Urban area & & & & $\begin{array}{c}0.0512^{* * * *} \\
(0.0150)\end{array}$ & & \\
\hline First stage coefficient on eligibility & & & & $\begin{array}{c}0.4610^{* * *} \\
(0.0220)\end{array}$ & $\begin{array}{c}0.4403^{* * *} \\
(0.0294)\end{array}$ & $\begin{array}{c}.4979^{* * *} \\
(0.0341)\end{array}$ \\
\hline Number of observations & 3,065 & 1,603 & 1,462 & 3,065 & 1,603 & 1,462 \\
\hline Median of Dep. Var. (Inelig. h'holds) & 0.75 & 0.75 & 0.75 & 0.75 & 0.75 & 0.75 \\
\hline Polynomial & 1 & 1 & 1 & 1 & 1 & 1 \\
\hline \multicolumn{7}{|l|}{ Education Aspirations } \\
\hline $\begin{array}{l}\text { (i) Probability of finishing } \\
\text { secondary school }\end{array}$ & $\begin{array}{l}-2.9927 \\
(3.8790) \\
{[0.4404]}\end{array}$ & $\begin{array}{c}4.1882 \\
(5.4902) \\
{[0.4455]}\end{array}$ & $\begin{array}{l}-0.4272 \\
(7.4126) \\
{[0.9540]}\end{array}$ & $\begin{array}{l}1.5017 \\
(3.7947) \\
{[0.6923]}\end{array}$ & $\begin{array}{c}8.6559 \\
(5.4832) \\
{[0.1144]}\end{array}$ & $\begin{array}{c}0.8432 \\
(7.2694) \\
{[0.9077]}\end{array}$ \\
\hline Female & & & & $\begin{array}{c}-1.9052^{* *} \\
(0.9232)\end{array}$ & $\begin{array}{c}-2.5225^{*} \\
(1.3298)\end{array}$ & $\begin{array}{l}-1.5377 \\
(1.2702)\end{array}$ \\
\hline Age & & & & $\begin{array}{c}-0.1012^{* *} \\
(0.0418)\end{array}$ & $\begin{array}{c}-0.1450^{* *} \\
(0.0623)\end{array}$ & $\begin{array}{l}-0.0625 \\
(0.0571)\end{array}$ \\
\hline Years of education of caregiver & & & & $\begin{array}{c}1.5463^{* * * *} \\
(0.1394)\end{array}$ & $\begin{array}{c}1.9360 * * * \\
(0.2172)\end{array}$ & $\begin{array}{c}1.2694^{* * *} \\
(0.1877)\end{array}$ \\
\hline Lives in Urban area & & & & $\begin{array}{l}1.9892^{*} \\
(1.1049)\end{array}$ & & \\
\hline First stage coefficient on eligibility & & & & $\begin{array}{c}0.4226^{* * *} \\
(0.0252)\end{array}$ & $\begin{array}{c}0.4197^{* * *} \\
(0.0349)\end{array}$ & $\begin{array}{c}.4580^{* * *} \\
(0.0493)\end{array}$ \\
\hline Number of observations & 3,945 & 2,036 & 1,909 & 3,945 & 2,036 & 1,909 \\
\hline Median of Dep. Var. (Inelig. h'holds) & 84.5 & 82.1 & 87.7 & 84.5 & 82.1 & 87.7 \\
\hline Polynomial & 1 & 1 & 2 & 1 & 1 & 2 \\
\hline $\begin{array}{l}\text { (ii) Probability of finishing } \\
\text { higher education }\end{array}$ & $\begin{array}{c}-14.2513^{* *} \\
(6.2775) \\
{[0.0232]}\end{array}$ & $\begin{array}{l}-11.1006 \\
(9.9204) \\
{[0.2632]}\end{array}$ & $\begin{array}{c}-17.8300^{* * *} \\
(6.1064) \\
{[0.0035]}\end{array}$ & $\begin{array}{c}-14.7113^{* *} \\
(6.0615) \\
{[0.0152]}\end{array}$ & $\begin{array}{l}-7.5763 \\
(9.8267) \\
\end{array}$ & $\begin{array}{c}-14.6267^{* *} \\
(6.1037) \\
{[0.0166]}\end{array}$ \\
\hline Female & & & & $\begin{array}{l}1.2341 \\
(1.0951)\end{array}$ & $\begin{array}{l}2.8796^{*} \\
(1.5884)\end{array}$ & $\begin{array}{l}-0.9737 \\
(1.5099)\end{array}$ \\
\hline Age & & & & $\begin{array}{l}0.1181^{* *} \\
(0.0512)\end{array}$ & $\begin{array}{l}0.1496^{*} \\
(0.0785)\end{array}$ & $\begin{array}{l}0.0813 \\
(0.0680)\end{array}$ \\
\hline Years of education of caregiver & & & & $\begin{array}{c}2.0806^{* * * *} \\
(0.1633)\end{array}$ & $\begin{array}{c}2.5916^{* * *} \\
(0.2554)\end{array}$ & $\begin{array}{c}1.7054^{* * *} \\
(0.2104)\end{array}$ \\
\hline Lives in Urban area & & & & $\begin{array}{c}6.2663^{* * *} \\
(1.3234)\end{array}$ & & \\
\hline First stage coefficient on eligibility & & & & $\begin{array}{c}0.4423^{* * *} \\
(0.0333)\end{array}$ & $\begin{array}{c}0.4224^{* * *} \\
(0.0476)\end{array}$ & $\begin{array}{c}0.4453^{* * *} \\
(0.0378)\end{array}$ \\
\hline Number of observations & 3,877 & 2,000 & 1,877 & 3,877 & 2,000 & 1,877 \\
\hline Median of Dep. Var. (Inelig. h'holds) & 59.1 & 64.0 & 76.1 & 59.1 & 64.0 & 76.1 \\
\hline Polynomial & 2 & 2 & 1 & 2 & 2 & 1 \\
\hline
\end{tabular}

Notes: This table presents estimates of $\tau$ from the second stage of the IV estimation. The eligibility on participation is the first-stage parameter $\delta$. Household clustered standard errors in parentheses. P values in squared brackets. Significance: $* * * \mathrm{p}<0.01, * * \mathrm{p}<0.05,{ }^{*} \mathrm{p}<0.1$. 
Table 5: Effect of Participation on Time Preferences for Current and Past Recipient Households

\section{Current Participants $\quad$ Past Participants ${ }^{1}$}

All Urban Rural All Urban Rural

Panel A: No covariates

\begin{tabular}{lcccccc} 
Program Effect & -0.0195 & -0.0521 & -0.0241 & 0.0090 & -0.0366 & -0.0173 \\
& $(0.0454)$ & $(0.0671)$ & $(0.0651)$ & $(0.0618)$ & $(0.1072)$ & $(0.0839)$ \\
& {$[0.6676]$} & {$[0.4377]$} & {$[0.7116]$} & {$[0.8837]$} & {$[0.7330]$} & {$[0.8365]$} \\
\hline Median of Dep. Var. (Inelig. h'holds) & 0.6404 & 0.6086 & 0.7040 & 0.6675 & 0.6581 & 0.6963 \\
& $(0.0335)$ & $(0.0463)$ & $(0.0464)$ & $(0.0258)$ & $(0.0465)$ & $(0.0327)$ \\
First Stage coefficient on eligibility & $0.5973^{* * *}$ & $0.5797 * * *$ & $0.6067 * * *$ & $0.6294^{* * *}$ & $0.6480^{* * *}$ & $0.6089 * * *$ \\
& $(0.0281)$ & $(0.0375)$ & $(0.0440)$ & $(0.0498)$ & $(0.0839)$ & $(0.0675)$ \\
Observations & 1,993 & 1,035 & 958 & 788 & 376 & 412 \\
\hline \hline
\end{tabular}

Panel B: Controlling for household consumption per capita

\begin{tabular}{lccc} 
Program Effect & -0.0238 & -0.0519 & -0.0326 \\
& $(0.0459)$ & $(0.0669)$ & $(0.0662)$ \\
& {$[0.6044]$} & {$[0.4380]$} & {$[0.6228]$} \\
\hline Median of Dep. Var. (Inelig. h'holds) & 0.6532 & 0.6334 & 0.7208 \\
& $(0.0352)$ & $(0.0516)$ & $(0.0489)$ \\
First Stage coefficient on eligibility & $0.5917^{* * *}$ & $0.5798^{* * *}$ & $0.5980^{* * *}$ \\
& $(0.0280)$ & $(0.0373)$ & $(0.0440)$ \\
Observations & 1,993 & 1,035 & 958
\end{tabular}

Notes: This table presents estimates of $\tau$ from the the second stage of the IV estimation; and the estimate of the effect of eligibility on participation from the first-stage, $\delta$. We use the number of polynomials at each side of the threshold found to be of best fit using the AIC criterion. Panel A presents the estimations without including covariates. Panel B presents the estimations controlling for households consumption per capita. Household clustered standard errors in parentheses. $\mathrm{P}$ values in squared brackets. Significance: ${ }^{* * *} \mathrm{p}<0.01, * * \mathrm{p}<0.05, * \mathrm{p}<0.1$. $^{1}$ Participating in the past but no longer eligible because there are no longer children aged 0 to 17 in the household. 


\section{Figures}

Figure 1: Histogram of outcome variables

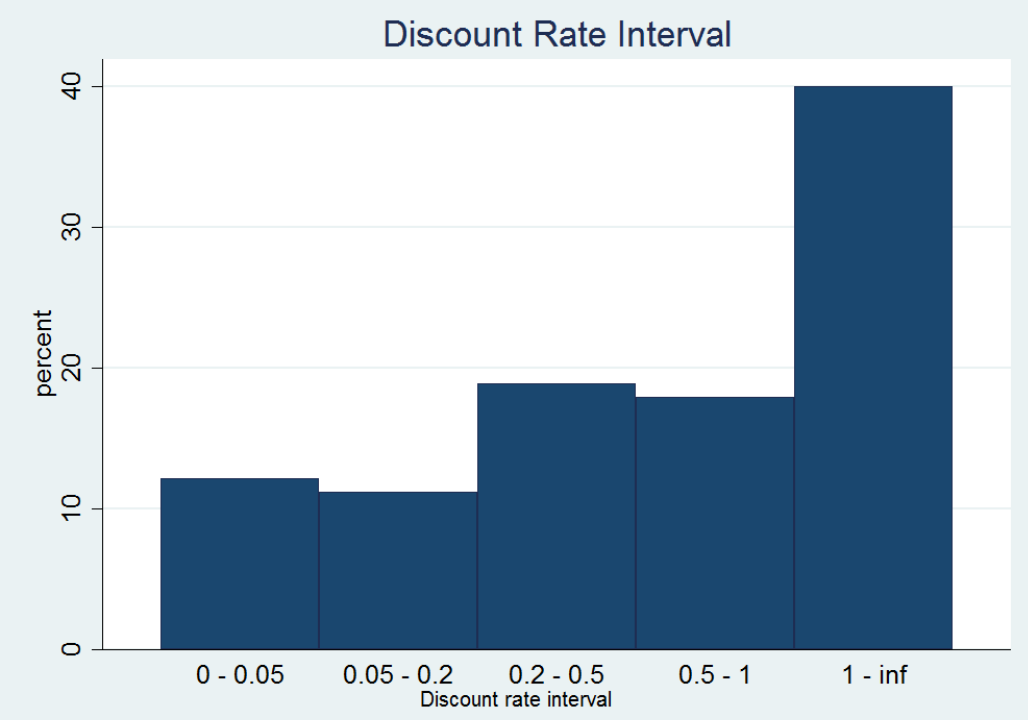


Figure 2: Probability of program participation by poverty score
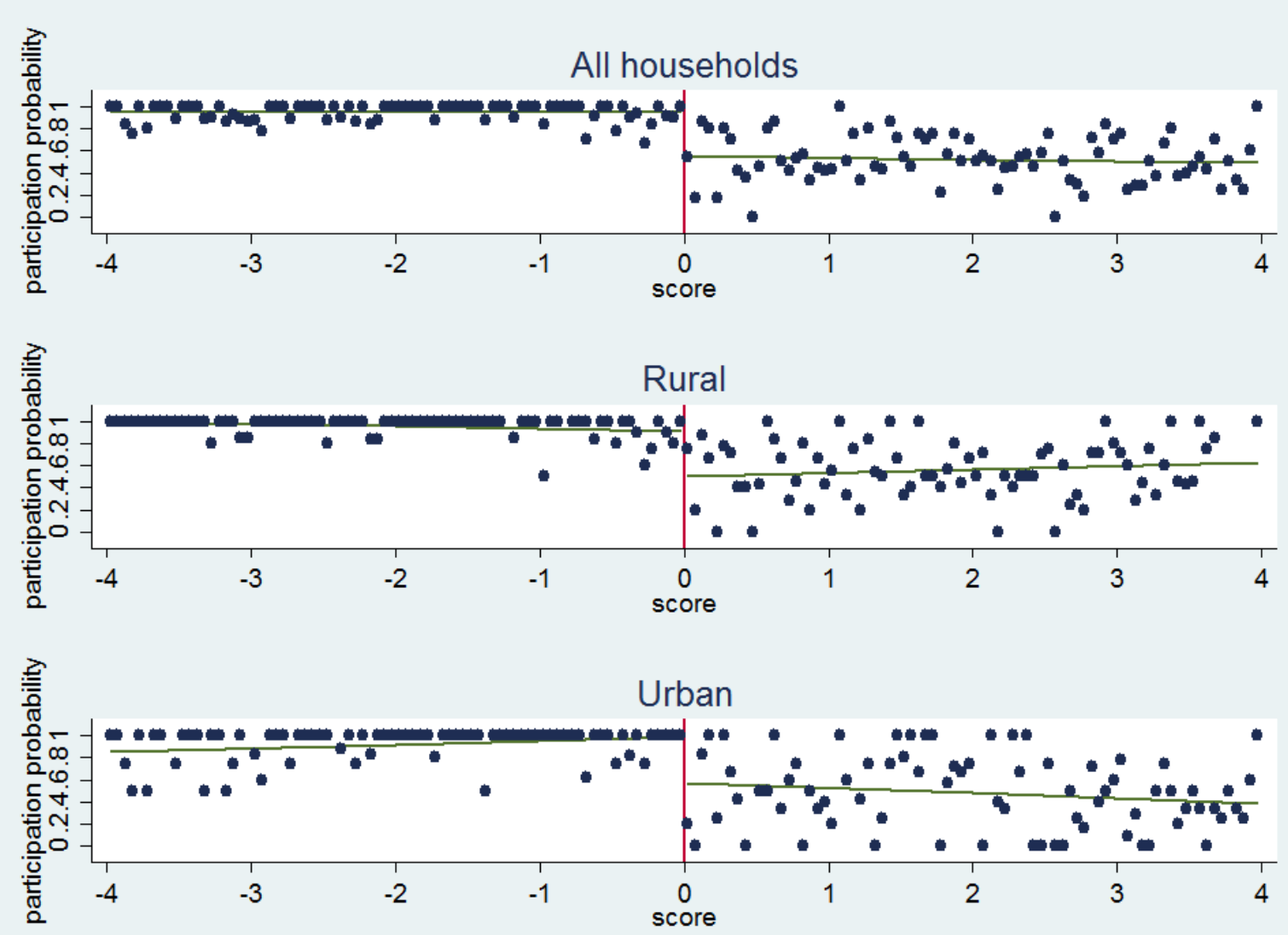
Figure 3: Distribution of the poverty index around the cut-off score

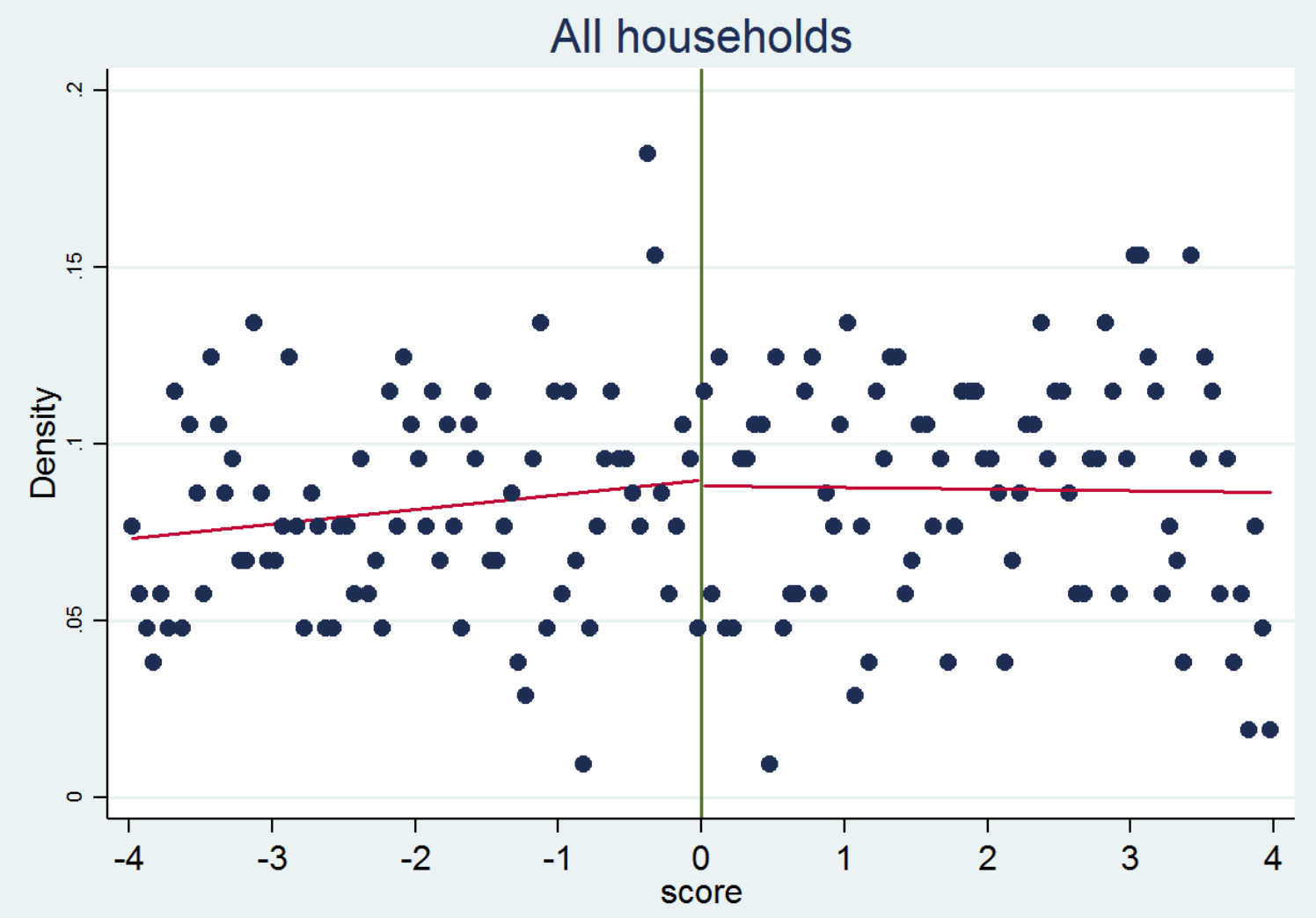


Figure 4: Effect of program participation on outcomes
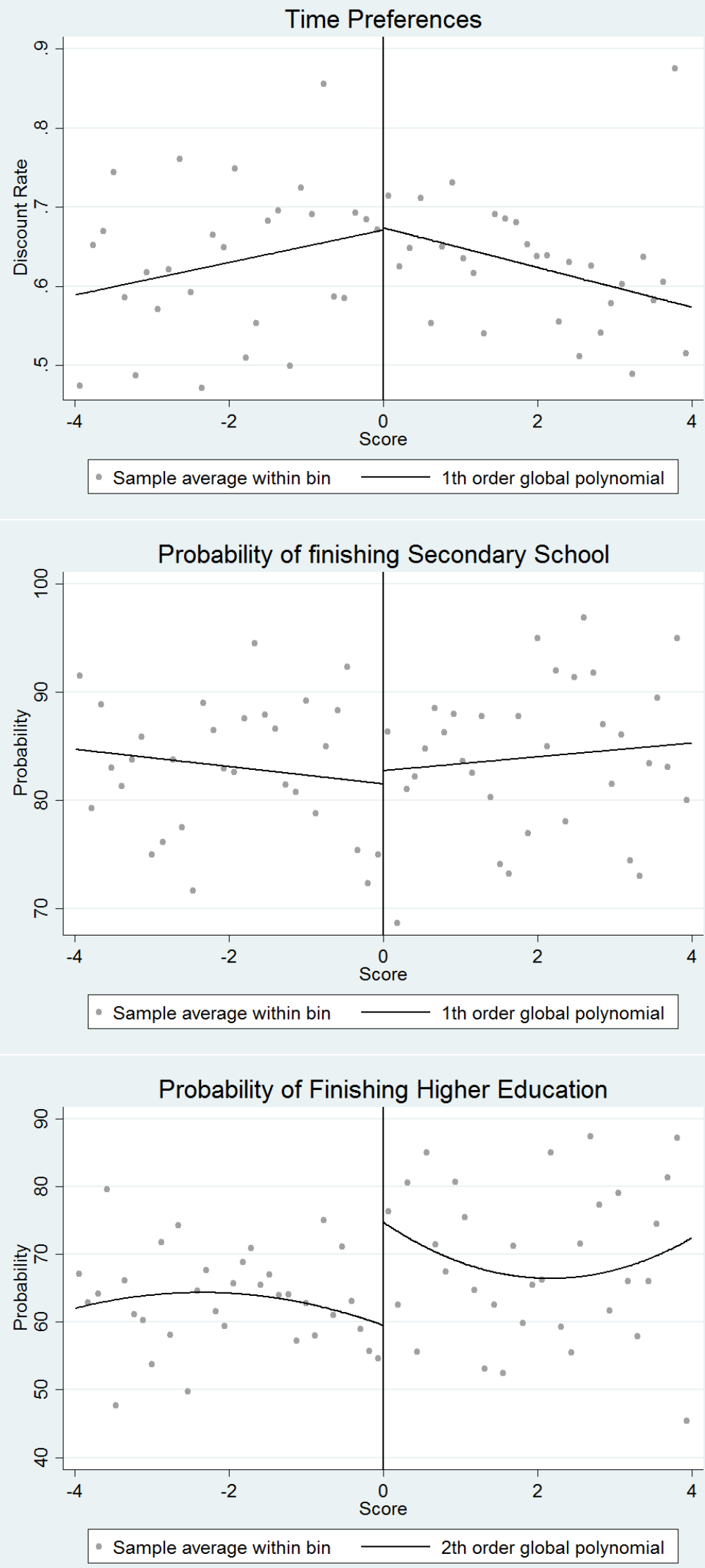


\section{A Appendix}

Table A1: Estimates of the Size of the Discontinuity in Program Participation at the Cut-off Poverty Score

\begin{tabular}{|c|c|c|c|}
\hline $\begin{array}{l}\text { Polynomial order on both sides } \\
\text { of the eligibility cut-off }\end{array}$ & All & Rural & Urban \\
\hline \multicolumn{4}{|c|}{ Panel A: Household level sample } \\
\hline 1 & $\begin{array}{c}0.4732^{* * *} \\
(0.0219)\end{array}$ & $\begin{array}{c}0.4438^{* * *} \\
(0.0296)\end{array}$ & $\begin{array}{c}0.5082^{* * * *} \\
(0.0338)\end{array}$ \\
\hline 2 & $\begin{array}{c}0.4526 * * * \\
(0.0310)\end{array}$ & $\begin{array}{c}0.4256^{* * * *} \\
(0.0424)\end{array}$ & $\begin{array}{c}0.4892^{* * *} \\
(0.0488)\end{array}$ \\
\hline 3 & $\begin{array}{c}0.3973 * * * \\
(0.0383)\end{array}$ & $\begin{array}{c}0.3756^{* * * *} \\
(0.0556)\end{array}$ & $\begin{array}{c}0.4307 * * * \\
(0.0603)\end{array}$ \\
\hline 4 & $\begin{array}{c}0.3380^{* * * *} \\
(0.0451)\end{array}$ & $\begin{array}{c}0.3349^{* * * *} \\
(0.0663)\end{array}$ & $\begin{array}{c}0.3529 * * * \\
(0.0714)\end{array}$ \\
\hline 5 & $\begin{array}{c}0.3212^{* * *} \\
(0.0511)\end{array}$ & $\begin{array}{c}0.2937^{* * *} \\
(0.0769)\end{array}$ & $\begin{array}{c}0.3324^{* * *} \\
(0.0827)\end{array}$ \\
\hline Number of observations & 3,065 & 1,603 & 1,462 \\
\hline
\end{tabular}

Panel B: Caregiver level sample

\begin{tabular}{lccc}
1 & $0.4302^{* * *}$ & $0.4256^{* * *}$ & $0.4483^{* * *}$ \\
& $(0.0251)$ & $(0.0349)$ & $(0.0378)$ \\
& $0.4446^{* * *}$ & $0.4291^{* * *}$ & $0.4607^{* * *}$ \\
& $(0.0333)$ & $(0.0478)$ & $(0.0498)$ \\
3 & $0.4145^{* * *}$ & $0.4367^{* * *}$ & $0.4131^{* * *}$ \\
& $(0.0422)$ & $(0.0625)$ & $(0.0649)$ \\
4 & $0.3822^{* * *}$ & $0.4163^{* * *}$ & $0.3400^{* * *}$ \\
& $(0.0507)$ & $(0.0721)$ & $(0.0803))$ \\
5 & $0.3768^{* * *}$ & $0.3965^{* * *}$ & $0.3336^{* * *}$ \\
& $(0.0569)$ & $(0.0819)$ & $(0.0938)$ \\
Number of observations & 3,945 & 2,036 & 1,909 \\
\hline \hline
\end{tabular}

Notes: A This is the preferred specification of the polynomial order based on the AIC criterion. Results for the same polynomial order on both sides. Household clustered standard errors in parentheses. Significance: ${ }^{* * *} \mathrm{p}<0.01,{ }^{* *} \mathrm{p}<0.05,{ }^{*} \mathrm{p}<0.1$. 
Table A2: Non Parametric RD Estimates of the Effect of Program Participation on Time preferences

\begin{tabular}{|c|c|c|c|c|c|c|}
\hline Bandwidth: & Optimal & 4 & 3 & 2 & 1 & 0.5 \\
\hline & \multicolumn{6}{|c|}{ All } \\
\hline \multicolumn{7}{|l|}{ Polynomial of order: } \\
\hline \multirow[t]{3}{*}{0} & 0.0125 & 0.0126 & 0.0018 & -0.0011 & -0.0168 & 0.0062 \\
\hline & $(0.0550)$ & $(0.0562)$ & $(0.0672)$ & $(0.0864)$ & $(0.1358)$ & $(0.2084)$ \\
\hline & {$[0.8203]$} & {$[0.8224]$} & {$[0.9788]$} & {$[0.9902]$} & {$[0.9015]$} & {$[0.9761]$} \\
\hline \multirow[t]{3}{*}{1} & -0.0205 & -0.0232 & -0.0115 & -0.0042 & -0.0005 & -0.0059 \\
\hline & $(0.1219)$ & $(0.1244)$ & $(0.1488)$ & $(0.1923)$ & $(0.2993)$ & $(0.3324)$ \\
\hline & [0.8663] & {$[0.8518]$} & [0.9383] & [0.9824] & [0.9987] & {$[0.9858]$} \\
\hline \multirow[t]{3}{*}{2} & -0.0096 & -0.0008 & 0.0001 & -0.0631 & 0.0465 & -0.0126 \\
\hline & $(0.1946)$ & $(0.1990)$ & $(0.2422)$ & $(0.3296)$ & $(0.3442)$ & $(0.3152)$ \\
\hline & {$[0.9607]$} & {$[0.9967]$} & {$[0.9996]$} & {$[0.8482]$} & {$[0.8926]$} & {$[0.9681]$} \\
\hline \multirow[t]{3}{*}{3} & 0.0097 & -0.0090 & -0.0602 & 0.0379 & 0.0274 & 0.3075 \\
\hline & $(0.2881)$ & $(0.2960)$ & $(0.3560)$ & $(0.3671)$ & $(0.3540)$ & $(0.3553)$ \\
\hline & {$[0.9731]$} & {$[0.9757]$} & {$[0.8658]$} & [0.9179] & {$[0.9382]$} & {$[0.3867]$} \\
\hline \multirow[t]{3}{*}{4} & -0.0773 & -0.0566 & 0.0010 & 0.0897 & -0.0177 & 0.3708 \\
\hline & $(0.3732)$ & $(0.3739)$ & $(0.3838)$ & $(0.3432)$ & $(0.3242)$ & $(0.4526)$ \\
\hline & {$[0.8358]$} & {$[0.8798]$} & {$[0.9980]$} & [0.7939] & {$[0.9564]$} & {$[0.4126]$} \\
\hline \multirow[t]{2}{*}{ Observations } & 1,482 & 1,453 & 1,101 & 738 & 369 & 190 \\
\hline & \multicolumn{6}{|c|}{ Rural } \\
\hline \multirow[t]{3}{*}{0} & -0.0078 & -0.0063 & -0.0172 & -0.0033 & 0.0676 & 0.2444 \\
\hline & $(0.0827)$ & $(0.0813)$ & $(0.0984)$ & $(0.1323)$ & $(0.2283)$ & $(0.4066)$ \\
\hline & [0.9247] & {$[0.9380]$} & {$[0.8613]$} & {$[0.9800]$} & {$[0.7671]$} & {$[0.5478]$} \\
\hline \multirow[t]{3}{*}{1} & -0.0182 & -0.0241 & 0.0518 & 0.1598 & 0.5146 & 0.5869 \\
\hline & $(0.1938)$ & $(0.1901)$ & $(0.2488)$ & $(0.3640)$ & $(0.7481)$ & $(0.9078)$ \\
\hline & {$[0.9252]$} & {$[0.8991]$} & {$[0.8350]$} & {$[0.6608]$} & {$[0.4915]$} & {$[0.5179]$} \\
\hline \multirow[t]{3}{*}{2} & 0.2140 & 0.2098 & 0.2941 & 0.4543 & 0.5002 & 0.2787 \\
\hline & $(0.4017)$ & $(0.3953)$ & $(0.5078)$ & $(0.7523)$ & $(0.9303)$ & $(0.7025)$ \\
\hline & {$[0.5943]$} & {$[0.5955]$} & {$[0.5624]$} & {$[0.5459]$} & {$[0.5908]$} & {$[0.6916]$} \\
\hline \multirow[t]{3}{*}{3} & 0.4047 & 0.4002 & 0.4872 & 0.7143 & 0.6292 & 1.1316 \\
\hline & $(0.6825)$ & $(0.6705)$ & $(0.8509)$ & $(1.1234)$ & $(0.9261)$ & $(1.5081)$ \\
\hline & {$[0.5532]$} & {$[0.5506]$} & [0.5669] & {$[0.5249]$} & [0.4969] & {$[0.4530]$} \\
\hline \multirow[t]{3}{*}{4} & 0.5560 & 0.5554 & 0.6859 & 0.6554 & 0.4548 & 3.4525 \\
\hline & $(0.9586)$ & $(0.9628)$ & (1.1041) & $(1.0579)$ & $(0.8537)$ & $(10.5589)$ \\
\hline & {$[0.5619]$} & {$[0.5640]$} & {$[0.5344]$} & {$[0.5356]$} & {$[0.5942]$} & {$[0.7437]$} \\
\hline \multirow[t]{2}{*}{ Observations } & 827 & 837 & 639 & 415 & 207 & 115 \\
\hline & \multicolumn{6}{|c|}{ Urban } \\
\hline \multirow[t]{3}{*}{0} & 0.0024 & -0.0035 & -0.0213 & -0.0403 & -0.1693 & -0.2451 \\
\hline & $(0.0689)$ & $(0.0763)$ & $(0.0896)$ & $(0.1040)$ & $(0.1401)$ & $(0.1837)$ \\
\hline & {$[0.9717]$} & {$[0.9639]$} & {$[0.8123]$} & {$[0.6985]$} & {$[0.2268]$} & {$[0.1822]$} \\
\hline \multirow[t]{3}{*}{1} & -0.0608 & -0.0838 & -0.1244 & -0.2031 & -0.3697 & -0.3540 \\
\hline & $(0.1383)$ & $(0.1487)$ & $(0.1562)$ & $(0.1782)$ & $(0.2495)$ & $(0.2516)$ \\
\hline & {$[0.6602]$} & [0.5730] & {$[0.4260]$} & {$[0.2546]$} & [0.1384] & [0.1594] \\
\hline \multirow[t]{3}{*}{2} & -0.1612 & -0.2007 & -0.2727 & -0.4740 & -0.2543 & -0.3092 \\
\hline & $(0.1818)$ & $(0.1864)$ & $(0.2157)$ & $(0.3034)$ & $(0.2503)$ & $(0.2261)$ \\
\hline & {$[0.3752]$} & {$[0.2815]$} & {$[0.2061]$} & [0.1182] & {$[0.3097]$} & [0.1714] \\
\hline 3 & -0.2851 & -0.3333 & -0.4901 & -0.3526 & -0.3322 & -0.1061 \\
\hline & $(0.2208)$ & $(0.2539)$ & $(0.3235)$ & $(0.2797)$ & $(0.2573)$ & $(0.2058)$ \\
\hline & {$[0.1967]$} & [0.1893] & [0.1298] & {$[0.2075]$} & {$[0.1965]$} & [0.6063] \\
\hline 4 & -0.3882 & -0.4948 & -0.4136 & -0.2254 & -0.3586 & -0.1399 \\
\hline & $(0.2912)$ & $(0.3336)$ & $(0.3076)$ & $(0.2371)$ & $(0.2294)$ & $(0.2548)$ \\
\hline & {$[0.1825]$} & [0.1380] & {$[0.1787]$} & {$[0.3417]$} & [0.1180] & [0.5830] \\
\hline Observations & 716 & 616 & 462 & 323 & 162 & 75 \\
\hline
\end{tabular}

Notes: This table presents non parametric estimates using rdrobust in Stata using different polynomial specification and bandwidths. The optimal bandwidth included was found using MSE-optimal proposed by Imbens and Kalyanaraman (2011). Optimal bandwidths used for all:4.1686, rural: 3.8891, urban: 4.895. P-values in square brackets. Significance: ${ }^{* * *} \mathrm{p}<0.01,{ }^{* *} \mathrm{p}<0.05,{ }^{*} \mathrm{p}<0.1$. 
Table A3: Non-Parametric RD Estimates of the Effect of Program Participation on Probability of finishing secondary school

\begin{tabular}{|c|c|c|c|c|c|c|}
\hline Bandwidth: & Optimal & 4 & 3 & 2 & 1 & 0.5 \\
\hline & \multicolumn{6}{|c|}{ All } \\
\hline \multicolumn{7}{|c|}{ Polynomial of order: } \\
\hline \multirow[t]{3}{*}{0} & -3.2472 & -2.6835 & -2.2831 & -3.7029 & -9.2611 & -16.5552 \\
\hline & $(3.9398)$ & $(4.5019)$ & $(5.3675)$ & $(6.7637)$ & $(10.1401)$ & $(14.1549)$ \\
\hline & {$[0.4098]$} & {$[0.5511]$} & {$[0.6706]$} & {$[0.5841]$} & {$[0.3611]$} & {$[0.2422]$} \\
\hline \multirow[t]{3}{*}{1} & -1.4966 & -4.3871 & -8.2958 & -17.2367 & -23.9345 & -24.8393 \\
\hline & $(8.0067)$ & $(9.0396)$ & $(10.3838)$ & $(13.0684)$ & $(19.8571)$ & $(26.9511)$ \\
\hline & {$[0.8517]$} & {$[0.6275]$} & {$[0.4243]$} & {$[0.1872]$} & {$[0.2281]$} & {$[0.3567]$} \\
\hline \multirow[t]{3}{*}{2} & -9.5742 & -14.5545 & -24.4853 & -19.8745 & -31.3398 & -17.4247 \\
\hline & $(11.4054)$ & (13.1938) & $(16.3257)$ & $(21.1354)$ & $(27.4774)$ & $(32.8710)$ \\
\hline & {$[0.4012]$} & {$[0.2700]$} & {$[0.1337]$} & {$[0.3470]$} & {$[0.2541]$} & {$[0.5960]$} \\
\hline \multirow[t]{3}{*}{3} & -19.5716 & -29.1384 & -22.2417 & -31.7396 & -19.6507 & -40.3840 \\
\hline & $(15.6735)$ & (19.2199) & $(22.5054)$ & $(28.1747)$ & $(34.4027)$ & $(60.5982)$ \\
\hline & {$[0.2118]$} & {$[0.1295]$} & {$[0.3230]$} & {$[0.2599]$} & {$[0.5679]$} & {$[0.5051]$} \\
\hline \multirow[t]{3}{*}{4} & -30.0676 & -24.8750 & -25.4846 & -36.1586 & -15.9358 & -82.1021 \\
\hline & $(20.6877)$ & $(25.3533)$ & $(28.4156)$ & $(29.1320)$ & $(40.5869)$ & $(353.5735)$ \\
\hline & {$[0.1461]$} & {$[0.3265]$} & {$[0.3698]$} & {$[0.2145]$} & {$[0.6946]$} & {$[0.8164]$} \\
\hline \multirow[t]{2}{*}{ Observations } & 2,056 & 1,691 & 1,260 & 845 & 416 & 221 \\
\hline & \multicolumn{6}{|c|}{ Rural } \\
\hline \multirow[t]{3}{*}{0} & -1.4267 & -1.8690 & -2.3887 & -7.2061 & -16.9961 & -21.3465 \\
\hline & $(5.0428)$ & $(5.8322)$ & $(6.8102)$ & $(8.5505)$ & $(12.7421)$ & $(17.3810)$ \\
\hline & {$[0.7772]$} & {$[0.7486]$} & {$[0.7258]$} & {$[0.3994]$} & {$[0.1823]$} & {$[0.2194]$} \\
\hline \multirow[t]{3}{*}{1} & -4.1104 & -9.1460 & -17.4078 & -26.0426 & -29.6774 & -26.8177 \\
\hline & $(9.5162)$ & (11.0892) & (13.2054) & $(17.0149)$ & $(24.1655)$ & $(32.6745)$ \\
\hline & {$[0.6658]$} & {$[0.4095]$} & {$[0.1874]$} & {$[0.1259]$} & {$[0.2194]$} & {$[0.4118]$} \\
\hline \multirow[t]{3}{*}{2} & -15.2030 & -26.6743 & -33.7556 & -24.8356 & -29.6066 & -24.9509 \\
\hline & (15.1068) & (17.5747) & $(21.4558)$ & $(24.3154)$ & $(33.8835)$ & $(40.4958)$ \\
\hline & {$[0.3142]$} & {$[0.1291]$} & {$[0.1157]$} & {$[0.3071]$} & {$[0.3822]$} & {$[0.5378]$} \\
\hline \multirow[t]{3}{*}{3} & -29.7427 & -36.3975 & -24.4389 & -38.2854 & -22.4428 & -59.1128 \\
\hline & $(20.4909)$ & $(24.9557)$ & $(24.8931)$ & $(34.0870)$ & $(41.6954)$ & $(85.9717)$ \\
\hline & {$[0.1466]$} & {$[0.1447]$} & {$[0.3262]$} & {$[0.2614]$} & {$[0.5904]$} & {$[0.4917]$} \\
\hline \multirow[t]{3}{*}{4} & -35.8803 & -22.8812 & -31.9123 & -31.6768 & -32.1029 & -165.9655 \\
\hline & $(25.9076)$ & $(26.4945)$ & $(32.8369)$ & $(36.3925)$ & $(54.0914)$ & $(333.3364)$ \\
\hline & {$[0.1661]$} & {$[0.3878]$} & {$[0.3311]$} & {$[0.3841]$} & {$[0.5529]$} & [0.6186] \\
\hline \multirow[t]{2}{*}{ Observations } & 1,257 & 984 & 734 & 479 & 224 & 126 \\
\hline & \multicolumn{6}{|c|}{ Urban } \\
\hline \multirow[t]{3}{*}{0} & -6.5745 & -6.1521 & -4.4022 & -0.8165 & -0.0560 & -10.2291 \\
\hline & $(6.5926)$ & $(7.0723)$ & $(8.9008)$ & (11.4326) & (18.0669) & $(25.7648)$ \\
\hline & {$[0.3186]$} & {$[0.3844]$} & [0.6209] & {$[0.9431]$} & {$[0.9975]$} & {$[0.6914]$} \\
\hline \multirow[t]{3}{*}{1} & 0.3102 & 0.9711 & 3.4456 & -6.1737 & -16.0279 & -26.1522 \\
\hline & $(15.2275)$ & $(16.2362)$ & (18.2430) & $(22.6379)$ & $(36.6693)$ & $(40.9819)$ \\
\hline & {$[0.9837]$} & {$[0.9523]$} & {$[0.8502]$} & {$[0.7851]$} & {$[0.6620]$} & {$[0.5234]$} \\
\hline \multirow[t]{3}{*}{2} & 2.5220 & 1.8234 & -12.0277 & -10.1630 & -40.3571 & -20.5479 \\
\hline & $(22.3572)$ & $(22.7281)$ & $(28.0595)$ & $(42.1104)$ & $(44.9273)$ & $(30.5540)$ \\
\hline & {$[0.9102]$} & {$[0.9361]$} & {$[0.6682]$} & {$[0.8093]$} & {$[0.3690]$} & {$[0.5013]$} \\
\hline 3 & -10.4066 & -18.5668 & -19.7121 & -27.4118 & -25.1864 & -33.3184 \\
\hline & $(29.3114)$ & $(32.9907)$ & $(47.7768)$ & $(50.4555)$ & $(40.6346)$ & $(47.6906)$ \\
\hline & {$[0.7226]$} & {$[0.5736]$} & {$[0.6799]$} & {$[0.5869]$} & {$[0.5354]$} & {$[0.4848]$} \\
\hline 4 & -35.5571 & -30.3859 & -18.5115 & -48.8685 & -12.2957 & 2.8183 \\
\hline & $(51.5218)$ & $(57.7437)$ & $(52.5157)$ & $(46.6165)$ & $(32.9372)$ & (80.3997) \\
\hline & {$[0.4901]$} & {$[0.5987]$} & {$[0.7245]$} & {$[0.2945]$} & {$[0.7089]$} & {$[0.9720]$} \\
\hline Observations & 751 & 707 & 526 & 366 & 192 & 95 \\
\hline
\end{tabular}

Notes: This table presents non parametric estimates using rdrobust in Stata using different polynomial specification and bandwidths. The optimal bandwidth included was found using MSE-optimal proposed by Imbens and Kalyanaraman (2011). Optimal bandwidths used for all:5.3556, rural: 5.9242, urban: 4.4459. P-values in square brackets. Significance: $* * * \mathrm{p}<0.01$, $* * \mathrm{p}<0.05, * \mathrm{p}<0.1$. 
Table A4: Non-parametric RD Estimates of the Effect of Program Participation on Probability of finishing Higher Education

\begin{tabular}{|c|c|c|c|c|c|c|}
\hline Bandwidth: & Optimal & 4 & 3 & 2 & 1 & 0.5 \\
\hline & \multicolumn{6}{|c|}{ All } \\
\hline \multicolumn{7}{|l|}{ Polynomial of order: } \\
\hline \multirow[t]{3}{*}{0} & $-17.6410^{* * *}$ & $-16.5436^{* * *}$ & $-17.7161^{* * *}$ & $-23.9554^{* * *}$ & $-34.7858^{* * *}$ & $-46.6409 * * *$ \\
\hline & $(5.8870)$ & $(5.0926)$ & $(5.9141)$ & $(7.3416)$ & $(11.2972)$ & $(17.1570)$ \\
\hline & {$[0.0027]$} & {$[0.0012]$} & {$[0.0027]$} & {$[0.0011]$} & {$[0.0021]$} & {$[0.0066]$} \\
\hline \multirow[t]{3}{*}{1} & $-36.7414^{* * *}$ & $-27.8015^{* * *}$ & $-37.1425^{* * *}$ & $-48.1799 * * *$ & $-61.5371^{* *}$ & $-81.3697^{* *}$ \\
\hline & (11.6828) & $(9.8920)$ & (11.7807) & $(15.6319)$ & $(25.9384)$ & $(40.9321)$ \\
\hline & {$[0.0017]$} & [0.0049] & {$[0.0016]$} & {$[0.0021]$} & {$[0.0177]$} & {$[0.0468]$} \\
\hline \multirow[t]{3}{*}{2} & $-57.4134^{* * *}$ & $-49.3728 * * *$ & $-57.4659 * * *$ & $-55.8529 * *$ & $-82.3082^{* *}$ & -71.5362 \\
\hline & $(20.3119)$ & $(15.9656)$ & $(20.4424)$ & $(26.9043)$ & $(41.3085)$ & $(45.3645)$ \\
\hline & {$[0.0047]$} & {$[0.0020]$} & {$[0.0049]$} & {$[0.0379]$} & {$[0.0463]$} & {$[0.1148]$} \\
\hline \multirow[t]{3}{*}{3} & $-59.5875^{* *}$ & $-62.7339^{* *}$ & $-59.6288^{* *}$ & $-80.2821^{* *}$ & -86.9621 & -100.5926 \\
\hline & $(28.9786)$ & $(24.8229)$ & $(29.2718)$ & $(40.7146)$ & $(53.3412)$ & $(91.6514)$ \\
\hline & {$[0.0398]$} & {$[0.0115]$} & {$[0.0416]$} & {$[0.0486]$} & {$[0.1030]$} & {$[0.2724]$} \\
\hline \multirow[t]{3}{*}{4} & $-72.5395^{*}$ & $-61.8488^{*}$ & $-73.1432^{*}$ & $-90.8623^{* *}$ & -80.4513 & -254.3610 \\
\hline & $(39.8336)$ & $(33.3991)$ & $(40.0059)$ & $(45.2434)$ & $(55.9678)$ & $(973.5879)$ \\
\hline & {$[0.0686]$} & {$[0.0641]$} & {$[0.0675]$} & {$[0.0446]$} & {$[0.1506]$} & {$[0.7939]$} \\
\hline \multirow[t]{2}{*}{ Observations } & 1,259 & 1,666 & 1,241 & 829 & 410 & 217 \\
\hline & \multicolumn{6}{|c|}{ Rural } \\
\hline \multirow[t]{3}{*}{0} & $-14.8065^{* *}$ & $-15.1652^{* *}$ & $-15.7824^{*}$ & $-22.4216^{* *}$ & $-32.3994^{* *}$ & -30.0043 \\
\hline & $(6.1341)$ & $(7.0145)$ & $(8.1227)$ & $(10.2173)$ & $(15.7189)$ & $(21.7499)$ \\
\hline & [0.0158] & [0.0306] & [0.0520] & {$[0.0282]$} & [0.0393] & {$[0.1677]$} \\
\hline \multirow[t]{3}{*}{1} & $-18.9721^{*}$ & $-24.5067^{*}$ & $-35.3695^{* *}$ & $-42.7297 * *$ & -38.4603 & -52.0154 \\
\hline & (11.5084) & (13.4683) & $(16.4515)$ & $(21.2282)$ & $(30.5084)$ & $(47.9274)$ \\
\hline & [0.0992] & [0.0688] & {$[0.0316]$} & {$[0.0441]$} & {$[0.2074]$} & {$[0.2778]$} \\
\hline \multirow[t]{3}{*}{2} & $-38.4937 * *$ & $-46.4529^{* *}$ & $-47.2846^{*}$ & -33.9303 & -40.7901 & -78.7961 \\
\hline & $(19.2417)$ & $(22.2037)$ & $(26.4772)$ & $(30.6717)$ & $(45.6920)$ & $(57.2949)$ \\
\hline & {$[0.0454]$} & {$[0.0364]$} & {$[0.0741]$} & {$[0.2686]$} & {$[0.3720]$} & {$[0.1690]$} \\
\hline \multirow[t]{3}{*}{3} & $-46.6180^{*}$ & -46.3702 & -35.5382 & -45.1439 & -81.1740 & -151.3831 \\
\hline & $(26.1615)$ & $(30.5956)$ & $(32.0167)$ & $(43.6172)$ & $(66.5588)$ & $(124.7766)$ \\
\hline & {$[0.0748]$} & {$[0.1296]$} & {$[0.2670]$} & {$[0.3007]$} & {$[0.2226]$} & {$[0.2250]$} \\
\hline \multirow[t]{3}{*}{4} & -44.7988 & -30.3748 & -39.1837 & -53.1280 & -111.5047 & -334.5936 \\
\hline & $(32.0782)$ & $(33.9449)$ & $(42.3730)$ & $(51.3576)$ & $(78.7350)$ & $(528.9071)$ \\
\hline & {$[0.1625]$} & {$[0.3709]$} & {$[0.3551]$} & {$[0.3009]$} & {$[0.1567]$} & {$[0.5270]$} \\
\hline \multirow[t]{2}{*}{ Observations } & 1,222 & 974 & 727 & 474 & 222 & 123 \\
\hline & \multicolumn{6}{|c|}{ Urban } \\
\hline \multirow[t]{3}{*}{0} & $-23.0829 * * *$ & $-26.7684^{* * *}$ & $-29.5196^{* * *}$ & $-34.0028 * * *$ & $-47.2128^{* * *}$ & $-78.5343^{* * *}$ \\
\hline & $(6.2935)$ & $(7.4817)$ & (8.9996) & (10.9467) & (16.6243) & (28.2908) \\
\hline & [0.0002] & [0.0003] & [0.0010] & {$[0.0019]$} & {$[0.0045]$} & {$[0.0055]$} \\
\hline \multirow[t]{3}{*}{1} & $-38.8867 * * *$ & $-41.7094^{* * *}$ & $-46.7719 * * *$ & $-64.4451^{* * *}$ & $-106.1862^{* *}$ & -123.2955 \\
\hline & (13.1689) & $(15.4440)$ & $(17.1961)$ & $(23.5597)$ & $(50.9285)$ & $(76.4542)$ \\
\hline & {$[0.0031]$} & {$[0.0069]$} & {$[0.0065]$} & [0.0062] & {$[0.0371]$} & {$[0.1068]$} \\
\hline \multirow[t]{3}{*}{2} & $-48.4049 * *$ & $-58.9793 * * *$ & $-81.7768^{* *}$ & $-103.5816^{*}$ & -141.6779 & -72.6629 \\
\hline & $(19.1612)$ & $(22.7715)$ & $(33.2940)$ & $(58.3159)$ & $(88.7659)$ & $(52.6006)$ \\
\hline & {$[0.0115]$} & {$[0.0096]$} & {$[0.0140]$} & {$[0.0757]$} & {$[0.1105]$} & {$[0.1672]$} \\
\hline 3 & $-68.2319^{* *}$ & $-96.7961^{* *}$ & -120.7826 & -145.4938 & -103.4190 & -56.4443 \\
\hline & $(28.1068)$ & $(44.1146)$ & $(75.7012)$ & $(99.7386)$ & $(78.9815)$ & $(75.9700)$ \\
\hline & {$[0.0152]$} & {$[0.0282]$} & {$[0.1106]$} & {$[0.1446]$} & {$[0.1904]$} & {$[0.4575]$} \\
\hline 4 & $-103.0158^{* *}$ & -145.0366 & -136.9585 & -138.9186 & -58.7039 & -6.0416 \\
\hline & $(48.8654)$ & $(106.9634)$ & $(99.6486)$ & $(88.3592)$ & $(53.0204)$ & (135.1609) \\
\hline & {$[0.0350]$} & {$[0.1751]$} & {$[0.1693]$} & {$[0.1159]$} & {$[0.2682]$} & {$[0.9643]$} \\
\hline Observations & 876 & 692 & 514 & 355 & 188 & 94 \\
\hline
\end{tabular}

Notes: This table presents non parametric estimates using rdrobust in Stata using different polynomial specification and bandwidths. The optimal bandwidth included was found using MSE-optimal proposed by Imbens and Kalyanaraman (2011). Optimal bandwidths used for all:3.0316, rural: 5.7083, urban: 5.6158. P-values in square brackets. Significance: $* * * \mathrm{p}<0.01, * * \mathrm{p}<0.05, * \mathrm{p}<0.1$. 
Figure A1: Effect of program participation on outcomes for individuals in urban areas

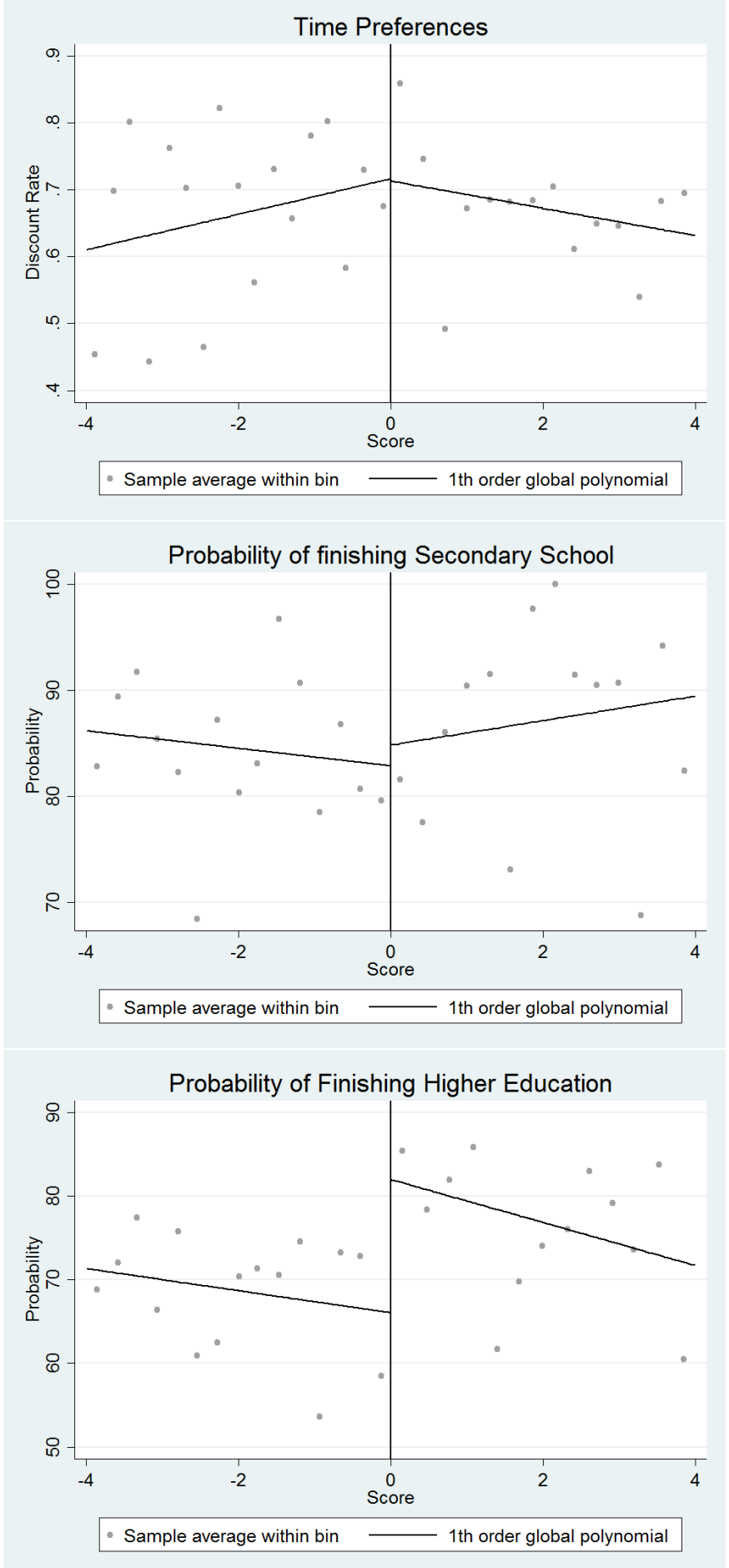


Figure A2: Effect of program participation on outcomes for individuals in rural areas

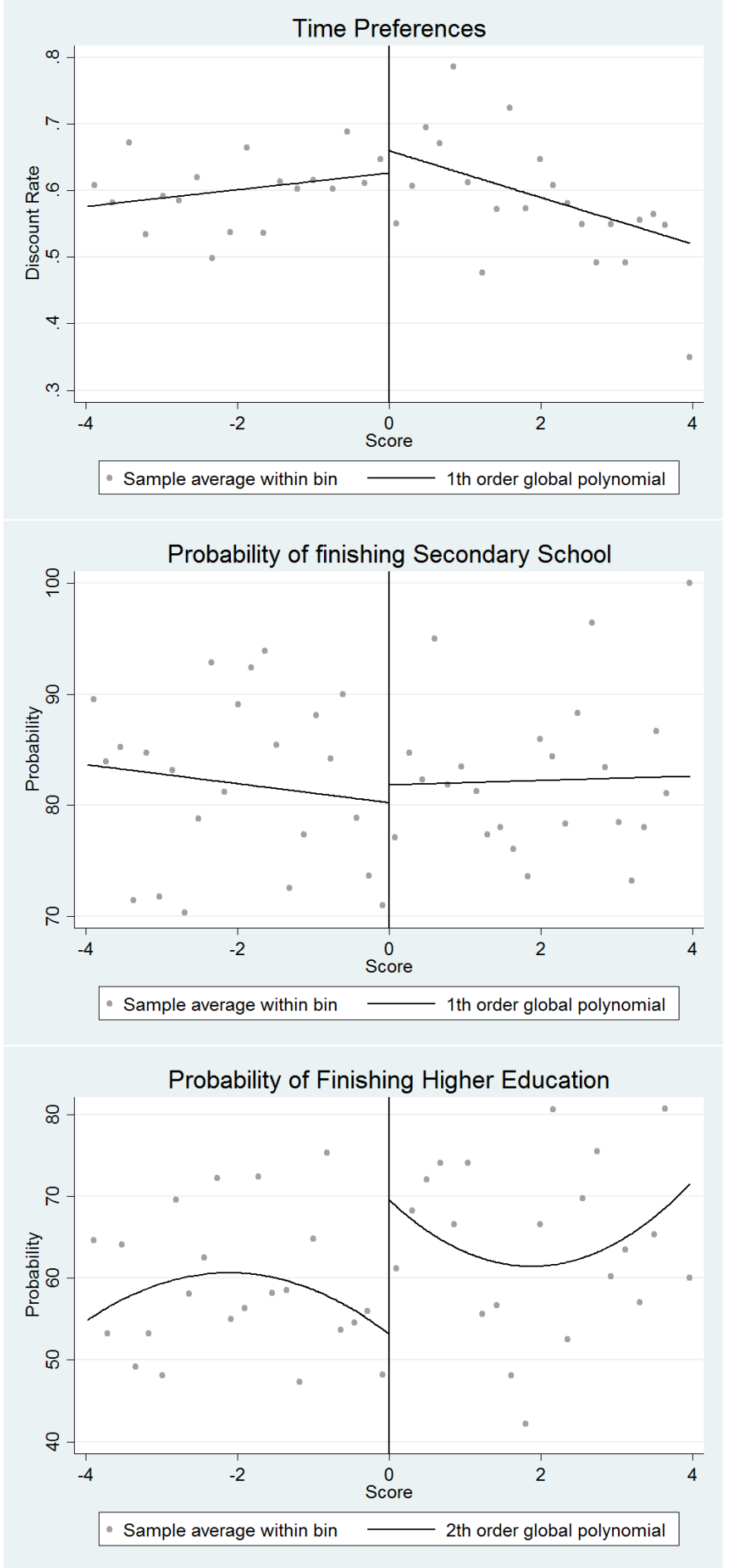

